\title{
STUDIES IN IRON TRANSPORTATION AND METABOLISM. IV. OBSERVATIONS ON THE ABSORPTION OF IRON FROM THE GASTRO-INTESTINAL TRACT 1,2
}

\author{
BY CARL V. MOORE, WM. R. ARROWSMITH,3 JO WELCH, AND \\ VIRGINIA MINNICH
}

\begin{abstract}
(From the Department of Medicine, Division of Research Medicine, Ohio State University, Columbus)
\end{abstract}

(Received for publication April 22, 1939)

Most of the problems of iron therapy which have troubled physicians during the past half century are fundamentally traceable to our ignorance of the mechanism by which iron is absorbed from the intestinal tract. Had that mechanism been understood, the discussions centering about the relative efficacy of inorganic and organic iron preparations would not have occurred, and hematologists would not now be troubled by the clinical observation that simple ferrous salts are apparently utilized more completely for hemoglobin formation than are the complex ferric salts, such as iron and ammonium citrate (5 to 11 inc.). Adequate experimental analysis of the factors involved in iron absorption has been delayed by the lack of a method sufficiently dependable to measure immediate absorption from the intestinal tract. Investigators have been forced to utilize indirect procedures which measure: (1) the difference, in a given period of study, between the amount of iron ingested and the amount excreted in the urine and feces $(12,13)$; (2) the amount of iron which "disappears" from an isolated segment of intestine (14); or (3) the total increase in circulating hemoglobin resulting from the therapeutic administration of iron in various forms. From the hemoglobin increase is then calculated the percentage of iron that has been utilized $(15,16$, 17). The first of these three approaches is open to the objection that no account can be taken of

1 Presented in part before the Tenth Annual Meeting of the Central Society for Clinical Research, Chicago, November 5-6, 1937, and in part before the Sixteenth International Physiological Congress, Zurich, August 14-21, 1938.

2 The authors wish to express their appreciation to John T. Read and Miss Olga Bierbaum for the assistance given by them in various phases of this investigation.

\& $\mathrm{M}$ \& $\mathrm{R}$ Dietetic Laboratory Fellow in Medical Research, 1937-1938. : the iron which may be absorbed and then excreted into the colon (18). McCance and Widdowson have, however, presented evidence which tends to show that such excretion is minimal (19). The technical difficulties are likewise significant in that the quantities of ingested and excreted (fecal) iron are large whereas the amount actually retained by the body has been shown to be comparatively small. Under such circumstances, the probable error in the determination of the large amounts administered orally and excreted in the feces is great and the period of study must at least be an extended one if the differences obtained are to be regarded as significant. The second approach is that in which, by a process of intubation, a known amount of iron is placed in an isolated segment of intestine. After a period of time, the contents of the segment are aspirated and the difference between the quantity of iron originally added and that recovered is assumed to be the amount that has been absorbed. Groen and Taylor (20) have demonstrated, however, that the difference is largely due to iron retained because of adsorption by the mucosa, rather than to actual absorption. While the third method has certain advantages, it not only is time consuming and indirect, but has recently been challenged on the ground that much more iron is actually absorbed and retained by the body following therapeusis than is utilized for immediate hemoglobin synthesis $(12,21,22$, 23).

If; however, iron absorption could be studied directly and immediately by measuring the amount added to the blood stream by the resorptive process, many of the difficulties would be eliminated. This approach became possible only after it had been demonstrated that iron is transported as plasma or serum iron $(2,4)$. Its use is dependent upon a knowledge of the forms and 
relationships of iron in the blood. Iron occurs in the blood stream in three states: as hemoglobin iron, as "easily split-off" iron, and as plasma iron. The first of these is by far the largest in amount and both its chemical nature and physiological function are inseparably linked with that of the hemoglobin molecule. "Easily split-off" iron constitutes 5 to 10 per cent of the total blood iron; its physiological function and chemical nature have not definitely been defined, but Barkan and Schales (24) have presented evidence to suggest that it is derived from a "pseudo-hemoglobin," possibly an intermediate step in the breakdown of hemoglobin into bile pigment. CortisJones and Lemberg are apparently in agreement with this point of view (25). It is entirely possible, as these authors suggest, that other iron containing pigments, degradation products of hemoglobin, are likewise present in the peripheral blood; but since these substances are closely related, physiologically at least, to Barkan's " pseudo-hemoglobin," they may be considered together with the latter as forming one type of blood iron compound. Serum or plasma iron is present in the relatively minute quantities of 50 to 180 micrograms per cent; its chemical nature is in question, but it probably is part of a complex radical, in the ferric state of ionization, in combination with serum globulin (1); the function of serum iron, as has been stated, is apparently that of iron transportation.

Demonstration has already been made of the facts that: (1) under basal conditions of iron intake and utilization, hourly variations in the serum iron level are comparatively slight (3); and (2) following the oral administration of a single large dose of various of the iron salts, there is a prompt rise in the serum iron fraction (2). This increase is apparent within the first half hour, reaches its maximum in $2 \frac{1}{2}$ to 5 hours, and then gradually falls to approximate the basal level by the end of 12 hours. The serum iron increase is not associated with a rise in the serum bilirubin content. Hemoglobin and "easily splitoff" iron fractions do not participate in the change (Figure 1).4 By following the serum

\footnotetext{
* Hahn, Bale, Lawrence, and Whipple (26) fed anemic dogs either ferric chloride or ferric sulphate which contained radioactive iron and noticed a prompt increase in radioactive iron, first in the plasma, and later in the red
}

iron responses to graded amounts of orally administered iron salts, therefore, under contrasting states of gastric acidity, during varying states of hematopoietic activity, and with experimentally altered conditions of intestinal motility and absorption, it should be possible theoretically to obtain considerable information about those factors which influence and control iron absorption. The present communication presents the results of such a study.

Statement has previously been made (2) of the fact that other workers have noted the increase in serum iron which occurs when iron salts are taken by mouth. Thoenes and Aschaffenburg (27) and Heilmeyer and Plötner (28) made, in addition, a comparison of the rise in serum iron produced by several of the iron salts under the influence of various conditions which might alter intestinal absorption. The results of these studies will be discussed in connection with the analysis of the data accumulated in this investigation. These authors were not primarily interested in the problem of iron absorption and did not, therefore, fully apply the serum iron absorption curve technique to the study of the subject.

It must be emphasized that, since serum (transport) iron is influenced not only by the iron being absorbed from the intestinal tract, but also by that being withdrawn from, or added to, the blood stream by the organs of storage, utilization, blood cell destruction, and excretion, the variations in serum iron do not measure the actual amount of iron being absorbed. The curve of serum iron does, however, indicate the fact and the degree of absorption. This method of study, furthermore, has a decided advantage in that it permits comparison of responses in the same individual not only to different iron preparations, but also to the same salt at different periods of hematopoietic activity, and under different gastro-intestinal influences.

cells. The following statement is made $(26$, p. 2286$)$ : "The rapid appearance of radioactive iron in the red blood cells is of great interest. A discussion of these observations must await further experiments to indicate the relationship of this iron to the hemoglobin of the various types of red blood cells (nucleated, immature, and mature)." In normal dogs the iron did not appear to be absorbed in comparable amounts. 


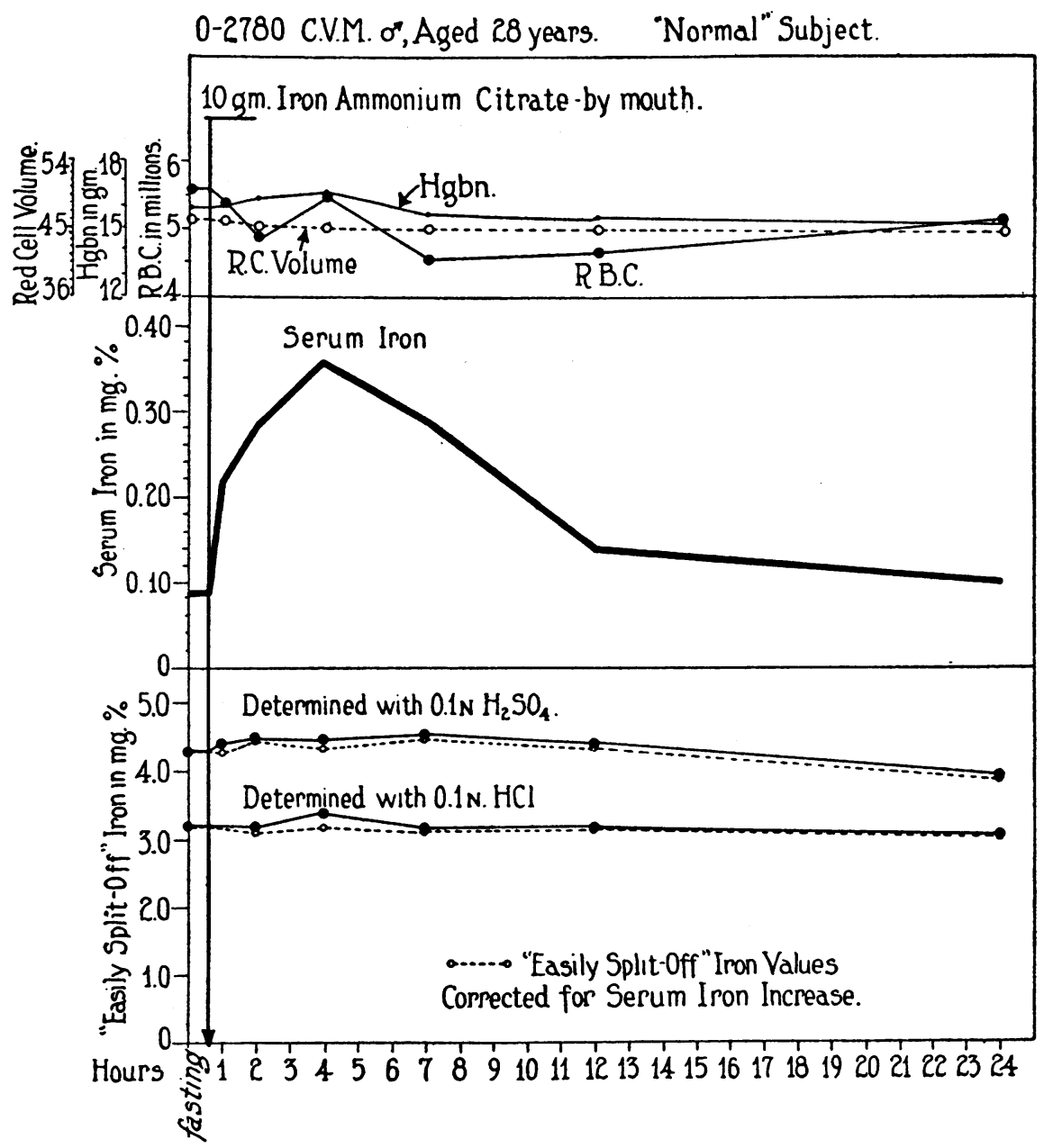

Fig. 1. Absorption of Iron from Intestinal Tract Reflected by an Increase in SERUM IRON

No change occurs in the "easily split-off" iron fraction.

The collection of serum specimens and the technic of quantitative iron analyses were carried out in the manner previously described $(1,3)$.

\section{The rôle of the lymph in iron absorption}

Since Gaule's (29) claim that when ferric chloride was given orally to rabbits he was able to demonstrate iron by staining methods in the thoracic duct lymph, there has been considerable question as to the function of the intestinal lymph passages in iron absorption. Gaule's experiments were criticized by Müller (30) on the ground that ferric chloride is a protein precipitant and could easily cause considerable damage to the readily injured mucous membrane of the rabbit's intestinal tract. Müller repeated the experiment using ferri-oxytartaricum and failed to demonstrate any increase of iron in the lymph of the thoracic duct. These experiments were performed before chemical methods of sufficient sensitivity to permit chemical quantitation of the iron had been developed. Further credence was given to the possibility of lymph transportation by the histological experiments of Höber (31), which tended to indicate that iron is resorbed intra-epithelially along with lipoid substances, whereas lipoid insoluble material seemed to be absorbed inter-epithelially. This conception of iron absorption as a function of living epithelial cells is compatible with Lintzel's (32), Fontès and Thivolle's (33) and Hahn's et al. (26) belief that the body is capable of selective absorption of iron 
-that is, of assimilating or rejecting it according to the needs at any given time.

In order to study this problem further, both the blood serum and the thoracic duct lymph iron were followed in a number of dogs after the giving of moderately large doses of iron by stomach tube. The dogs were prepared for experiment by being fasted for 18 hours. They were then fed a meal which consisted of one-half pound of lard and a small amount of ground beef muscle. Four to 5 hours later, the animals were anesthetized by intra-peritoneal injection of nembutal. The thoracic duct was isolated and cannulated. "Fasting" lymph and serum specimens were obtained and the iron salt, dissolved in $100 \mathrm{cc}$. of water, was permitted to run into the stomach through an ordinary lavage tube. All of the lymph was collected into $50 \mathrm{cc}$. paraffined centrifuge tubes; the samples were pooled for each successive 30 - or 60-minute period and centrifugalized to rid them of any red cells present. Serum specimens were collected at hourly intervals from blood obtained by femoral arterial puncture. Since observations were continued for 6 to 10 hours or more, and since considerable fluid was withdrawn from each animal, as blood and lymph, subcutaneous injections of $100 \mathrm{cc}$. saline were made throughout the course of the experiment at intervals of $11 / 2$ to 2 hours. Control hematocrit determinations, total cell counts, and hemoglobin estimations were likewise made. That the iron level in both serum and lymph was relatively constant under the conditions of "ironfasting " obtained in these animals with an undisturbed hematopoietic equilibrium, is indicated in the representative data presented in Figure 2. These results of 1 experiment in which 2 grams of ferrous sulphate were given are tabulated in Figure 3. The serum iron slowly increased to approximately twice its basal level, remained at that comparatively high figure for several hours, and then began to fall slightly by the time the experiment was terminated. The rise of iron in the lymph, however, was not nearly as great, and occurred much more slowly. It is interesting to note that the total amount of lymph collected in the 6 hours of observation was only $161 \mathrm{cc}$. and that the total increase of iron in the whole of that volume was not as great as the increase in 100 cc. of serum at the height of the serum iron absorption curve.

The delayed increase in lymph iron is not diffcult to explain since lymph drains the intercellular fluid and the latter is supplied, in part at least, from the blood stream. It is natural, then, to expect that a rise in serum iron would be reflected by a rise of that metal in the lymph. Experimental confirmation of that postulate was ob-

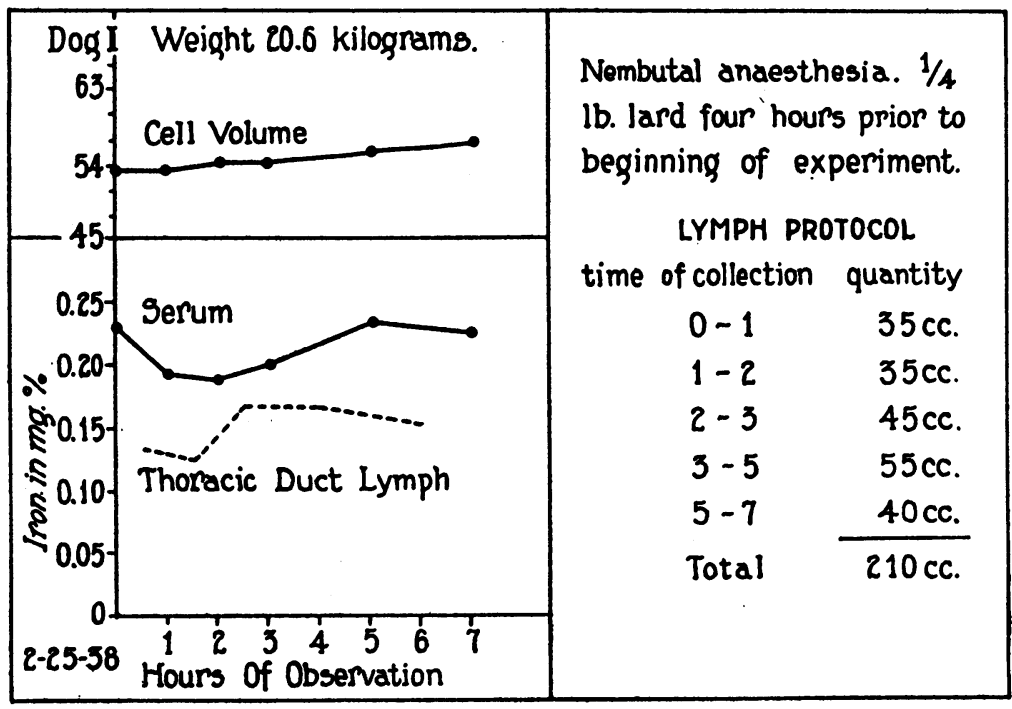

Fig. 2. Relative Constancy of Serum and Thoracic Duct Lympe Iron under "Iron-Fasting" Conditions in the Dog 


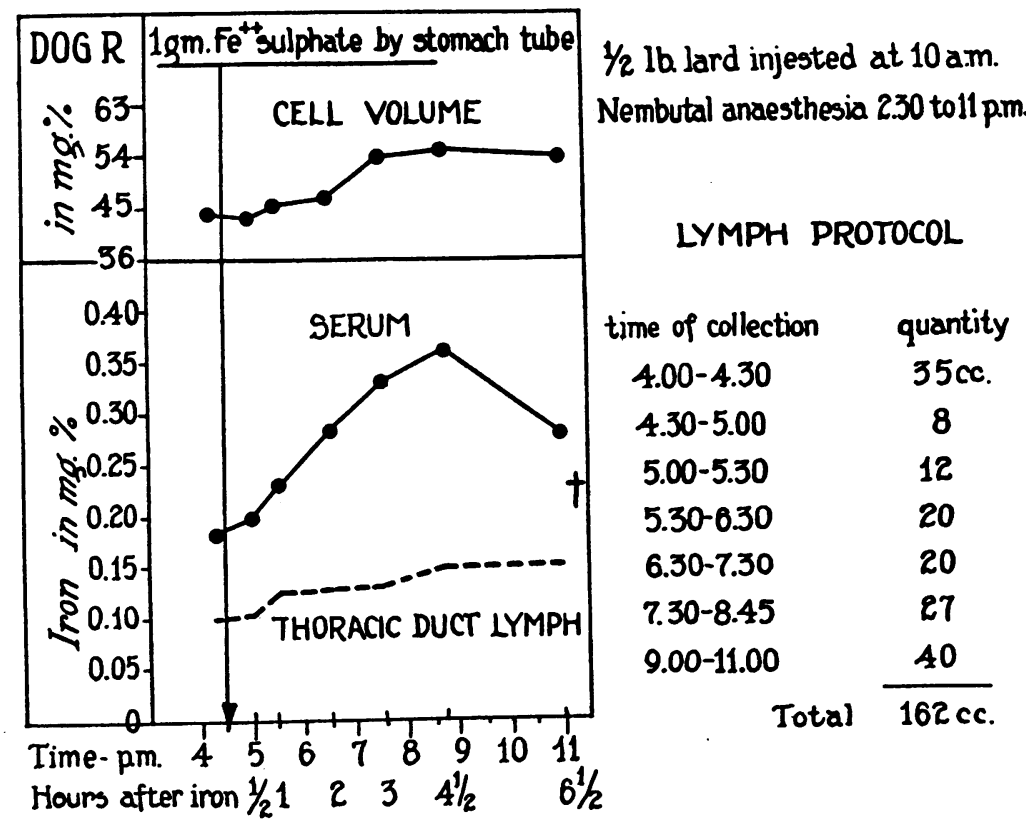

Fig. 3. Iron in Blood Serum and Thoracic Duct Lymph Following Oral Administration of Single Dose of Ferrous Sulphate

tained by injecting iron intravenously into dogs after the thoracic duct had been cannulated. Under these conditions the serum iron was increased immediately to high levels $(1 \mathrm{mgm}$. per $100 \mathrm{cc}$. or more) and fell slowly during the subsequent 12 hours to approximate the pre-injection level. Iron in the lymph was increased within half an hour, reached its maximum rise at the end of 2 or 3 hours, and then slowly began to fall (Figure 4). In no case did the rise in thoracic duct lymph iron exceed 300 micrograms per cent. These experiments serve to show rather conclusively that resorption of iron from the intestinal tract occurs directly into the blood stream rather than by way of the intermediate route of the intestinal lymph channels.

\section{Rate of disappearance of iron from the blood stream}

Before continuing further, it was obviously necessary to know something about the rate at which iron disappears from the blood stream. Starkenstein and Weden (34a) and Barkan (35) have shown that when iron is added to whole blood in vitro, all of the added iron can be recovered from the serum portion. We have demonstrated that when iron salts are injected intra- venously, the only blood iron fraction to show an increase is the serum iron fraction. In order to obtain information as to the rate of disappearance of added iron from the serum, therefore, sufficient quantities of various iron salts were injected into dogs to provide one milligram of the metallic metal per kilogram of body weight. The salts were first dissolved in water and then diluted with several parts of normal saline and injected slowly into one of the leg veins. Serum samples were collected immediately before the injection, and 5 minutes, 1 hour, 3 hours, 5 hours, 8 hours, and 12 hours after the administration. The animals were kept anesthetized throughout the experimental period.

As is obvious from Figures 5 and 6, one milligram of iron per kilogram of body weight given intravenously in the form of a soluble salt was sufficient to increase the level of serum iron from an initial value of about $0.2 \mathrm{mgm}$. per cent to from 1.2 to $1.5 \mathrm{mgm}$. per cent. The subsequent fall was a gradual one so that about 12 hours were required before the basal level was again approximated. There was apparently no difference in the rapidity with which ferric iron given as a simple (ferric chloride) or combined (ferric ammonium sulphate) salt was removed (Figure 5). 


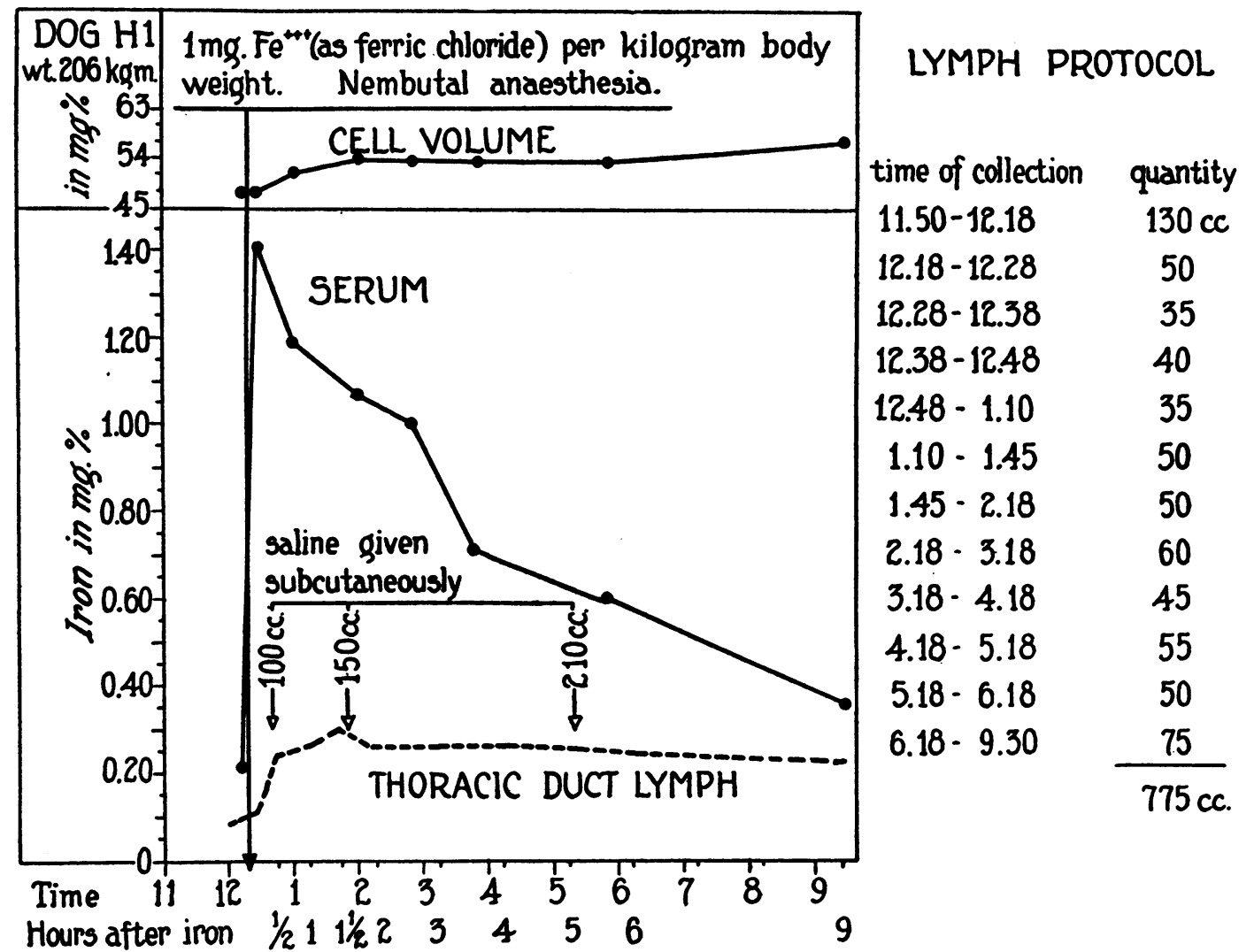

Fig. 4. Appearance of Iron in Thoracic Duct Lymph after Intravenous Administration of Iron To A DoG

$1 \mathrm{mg}, \mathrm{Fe}^{+++}$(Ferric Ammonium Sulphate) per kilogram body wt.,intravenously.

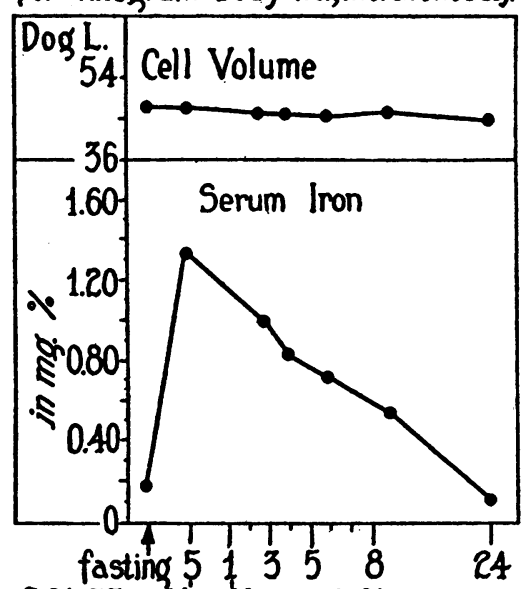

7-21-37 Min. Hours of Observation
$1 \mathrm{mq.Fe} \mathrm{e}^{+++}$(Ferric Chloride) per kilogram body wt, intravenously.

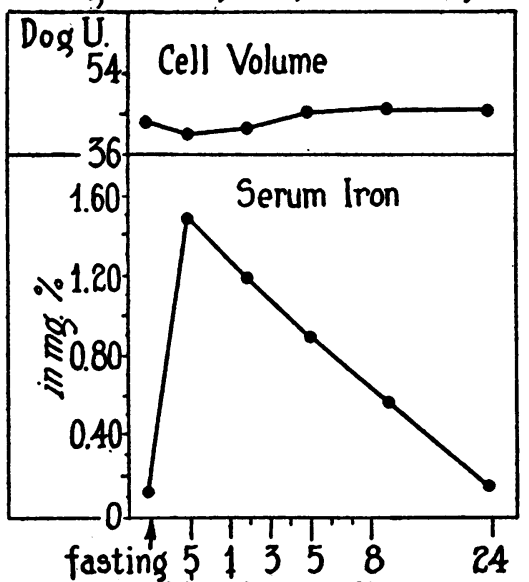

10-22-37 Min Hours of Observation
Img. Fe $e^{+++}$(Colloidal Ferric hydroxide) per kilogram body weight, intravenously.

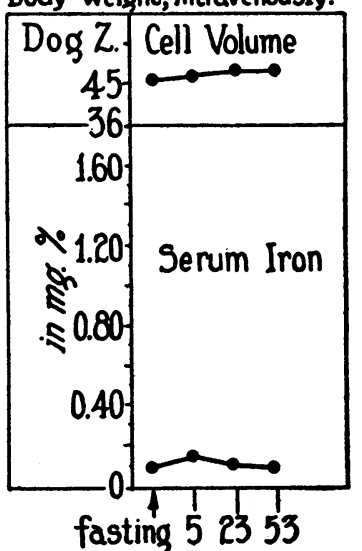

10-22-37 Minutes

Fig. 5. Comparison of Rates of Disappearance of Various Forms of Ferric Iron from the Blood Stream after Intravenous Administration 
Img. Feas ferrous and ferric ammonium $1 \mathrm{mg}$. Fe as ferrous and ferric sulphate per kilogram body weight.

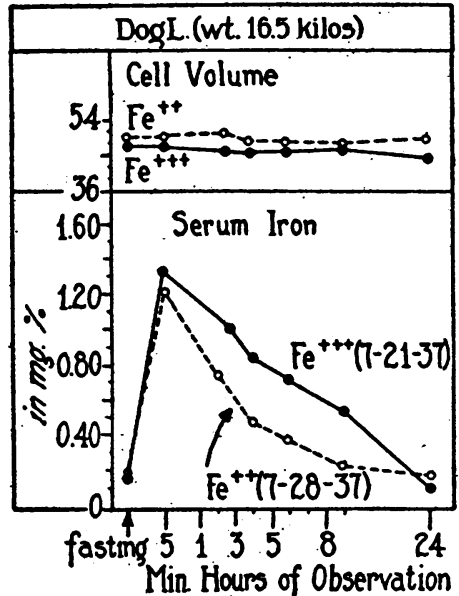

Fig. 6. chloride per kilogram body weight.

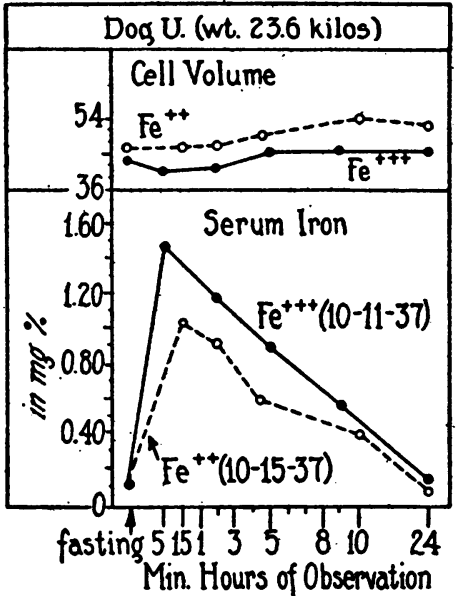

1mo. Fe as ferrous sulphate and ferric chloride per kilogram body weight.

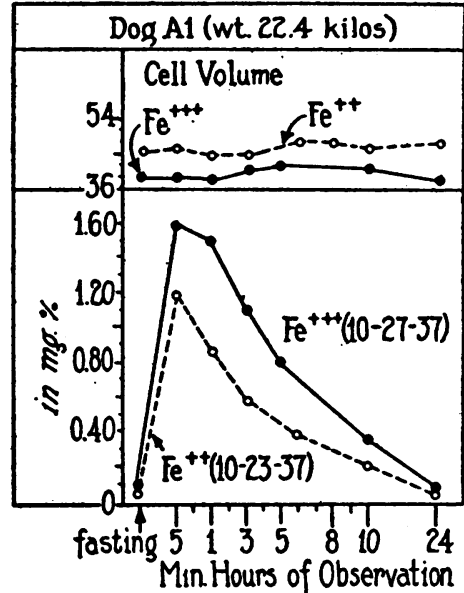

Disappearance of Ferrous and Ferric Iron from the Blood Streak AFTER INTRAVENOUS ADMINISTRATION

Nembutal anaesthesia used throughout duration of experiment. Iron administered intravenously in each instance immediately after fasting specimen.

When colloidal ferric hydroxide was used, however, the immediate rise was comparatively small and the rate of disappearance rapid enough to be complete within 10 to 15 minutes. This result is not surprising since it has been known for a long time that colloidal ferric hydroxide is taken up by the reticulo-endothelial cells (36, 37). In a number of animals, the fall in serum iron following the administration of comparable amounts of soluble ferrous and ferric iron to the same animal was followed (Figure 6). In each instance, irrespective of whether simple or combined salts were used, the height to which the serum iron values rose was less with the ferrous salts than with the ferric. The explanation for this phenomenon is not clear, since Starkenstein and Harvalik (38) have shown that ferrous iron is almost immediately oxidized to the ferric state on contact with whole blood.

\section{Height of serum iron response compared with amount of iron administered}

The most obvious objection to the use of the serum iron increase as an index of intestinal absorption of iron is that iron is a protein precipitant and for that reason may cause enough injury to the intestinal mucosa to permit a portion of the large amounts administered to pass through into the blood stream. In order to test the validity of this objection, and to establish at the same time the size of the dose that could best be used for future comparisons, several observations were performed on the relationship between the height of the serum iron increase and the size of the iron dose. In one such instance, the subject being a young male with normal gastric acidity, single doses of ferric sodium citrate were given on each of 4 different observation days in quantities that supplied successively $2.7,5.4,8.1$, and $10.7 \mathrm{mgm}$. of iron per kilogram of body weight (Figure 7). Serum specimens were collected immediately before the iron was ingested, and at approximately $1,21 / 2,5,8$, and 12 hours thereafter. This routine of blood collection was followed for all the studies made on human patients except that the 12 -hour specimen was occasionally omitted. The response to $2.7 \mathrm{mgm}$. of iron per kilo was approximately one-half the response to $5.4 \mathrm{mgm}$., and one-third of that to $8.1 \mathrm{mgm}$. per kilo. With the largest dose, 10.7 mgim. per kilo, considerable abdominal discomfort was experienced and a diarrhea developed within a few hours. It is interesting to note that the maximum increase above the initial level fol- 


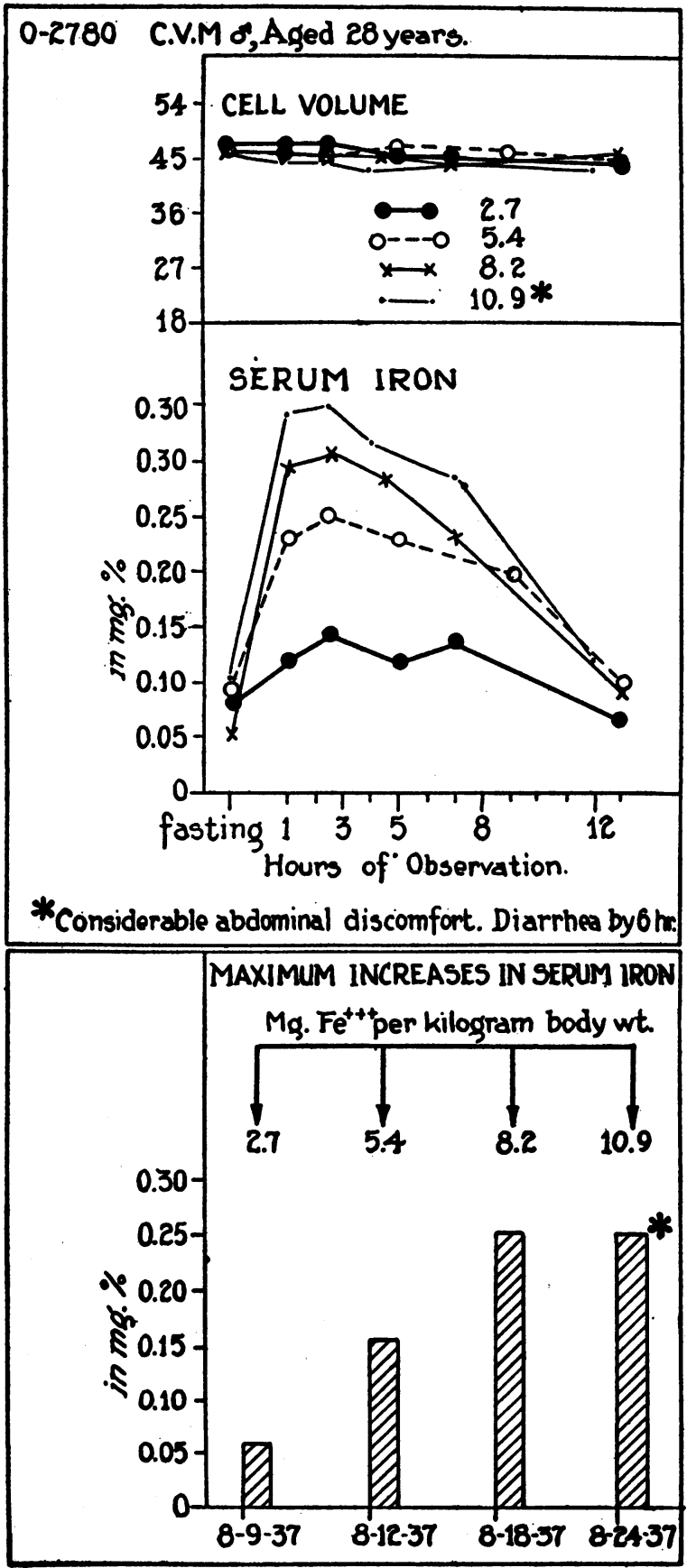

Fig. 7. Rise in Serum Iron Values following Single Oral Doses of Ferric Sodium Citrate in a "Normal" SUbJEct

lowing this amount was no greater than it had been after the $8.1 \mathrm{mgm}$. dosage. It is probable that the increased intestinal irritation was attended by increased motility so that the iron was swept along the absorbing portion of the small intestine at a rate that was too rapid to permit of optimum absorption.

A similar set of observations is tabulated in Figure 8. The subject was again a young male with normal gastric acidity and undisturbed erythropoiesis. He was given successively 2,4 , and $6 \mathrm{mgm}$. of iron per kilogram of body weight as ferric ammonium sulphate on each of 3 days, and comparable dosages of ferrous ammonium sulphate on 3 additional days. With both valence forms, the response to the $4 \mathrm{mgm}$. per kilo dose was approximately twice that to half the amount. The largest dose of iron, however, again caused considerable gastric distress and abdominal cramps, and again the serum iron increase was not directly proportional to the quantity given. The rise in serum iron following any given iron administration, therefore, is apparently roughly proportional to the amount of the metal administered, up to that point at which the intestinal irritation becomes great enough to alter motility and to interfere with the absorptive process.

\section{Relative constancy of serum iron rise produced by ingestion of identical amounts of ferrous sulphate in the same subject}

As another control of the applicability of this method to the study of iron absorption, it was necessary to determine how constant the serum iron increase produced by a given dose of iron might be in any particular subject. The individuals who volunteered for this study were afebrile and in apparent hematologic equilibrium. Ferrous sulphate was arbitrarily chosen as the salt to be used and was given in identical amounts on each of 3 or 4 different observation days. The absorption curves produced closely paralleled each other in every subject (Figures 9, 10, 12, $13,19)$ and were used as a standard of reference for comparing the relative degrees of absorption produced by other iron salts or by ferrous sulphate under the influence of certain specific factors to be described later. In order to make such a comparison easier, the limits of variation in response to these several administrations of ferrous sulphate were drawn as striated areas on the subsequent charts. 
0-3757 C.F.ó,Aged 32 years. Normal Gastruc Acidity

$2 \mathrm{mg}$. Fe per kilogram body wh

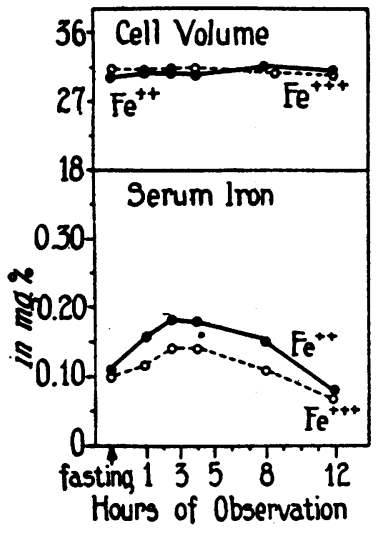

$4 \mathrm{mg}$. Fe per kilogram body wt.

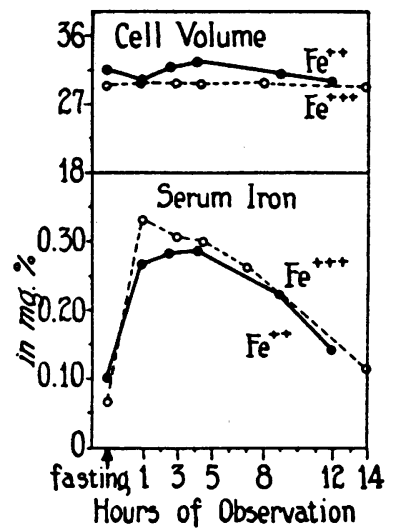

$6 \mathrm{mg}$. Fe per kilogram body wt.

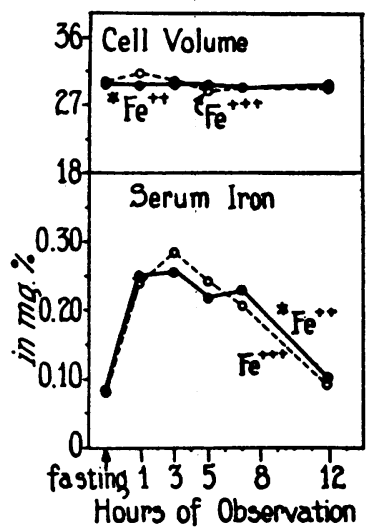

Summary of Serum Iron Responses
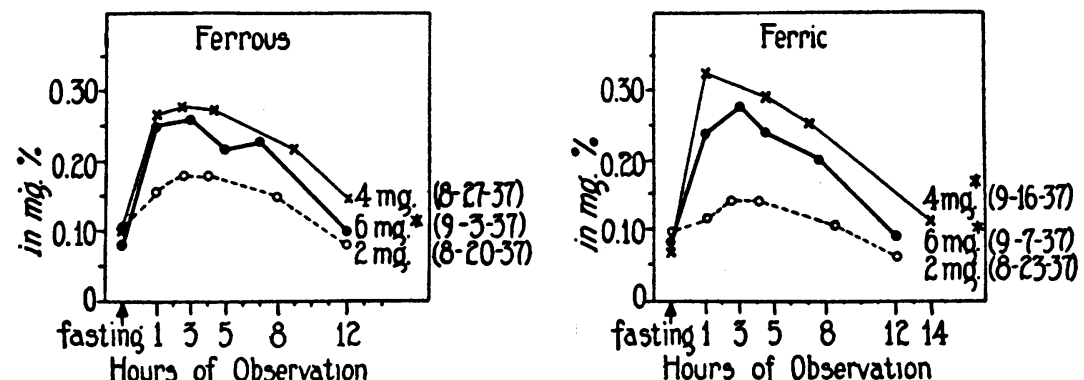

Ferrous iron given as ferrous ammonium sulphate.

Ferric iron given as ferric ammonium sulphate.

* Gastric distress, abdominal cramps, and diarrhea following administration.

Fig. 8. Increases in Serum Iron Values Following Oral Administration of Ferrous and Ferric Ammonium Sulphate in a "Normal" Subject

Comparison of the serum iron absorption curves produced by various of the water soluble ferrous salts

Starkenstein in 1928 (39) suggested that both ferrous and ferric iron were absorbed from the intestinal tract and that ferrous sulphate was resorbed less readily than was ferrous chloride. The anion was thought to be the determining factor in causing the differences in rate of absorption. Wallbach (40), using a histological technique, came to essentially the same conclusion: that the anion to which iron was bound was of greater importance than solubility of the salt or chemical properties of the metallic portion of the molecule.

This question seemed an ideal one for study by means of serum iron absorption curves. Comparable amounts of various ferrous salts were given to a number of subjects both with and without normal gastric acidity. Ferrous chloride, ferrous cevitamate, ferrous gluconate, ferrous carbonate, and ferrous ammonium sulphate were found to give serum iron rises comparable to those produced by ferrous sulphate both in individuals with a normal amount of free $\mathrm{HCl}$ in their gastric contents and in those with a histamine refractory achlorhydria (Figures 9, 10, $12,13)$. The relatively insoluble ferrous phosphate, on the other hand, caused no appreciable change in serum iron values (Figure 14). Thoenes and Aschaffenburg found that ferrous chloride and a ferrous preparation known as 


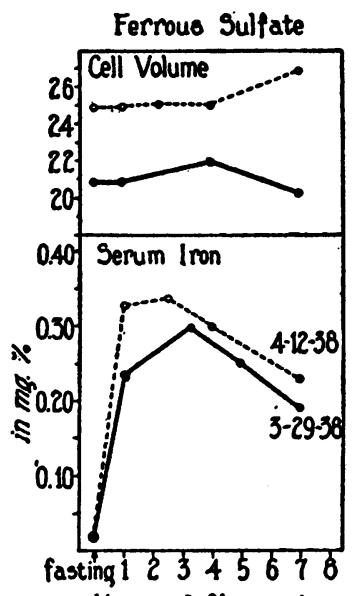

Hours of Observation
0-4057 G.W. o. weight 50 kilogram.

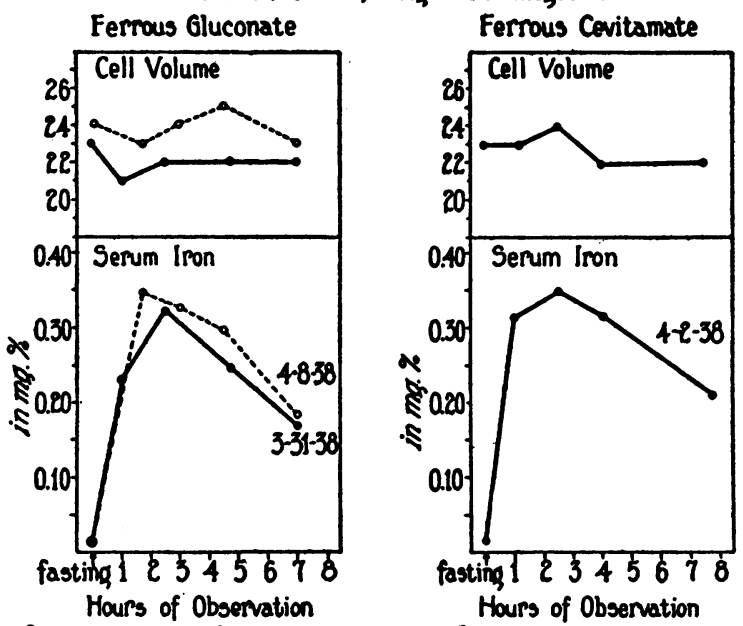

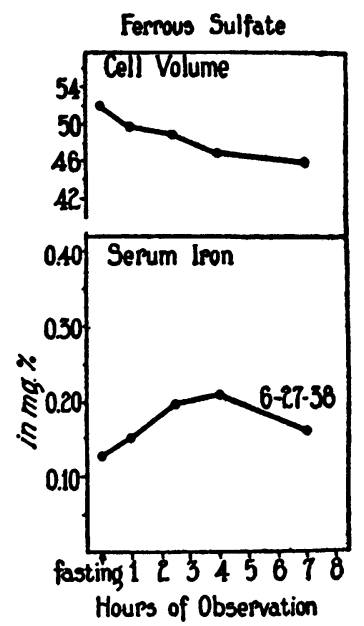

$4 \mathrm{mg}$. Fe per kilogram body weight. One piece toast and one cup coffee given 2 hr. before observations.

Fig. 9. Serum Iron Increases in an Adult Male with a Hypochromic, Microcytic Anemia and Normal. Gastric Acidity

0.4080 H.MCD. o", Aged 30 years, weight 67.7 kılogram. Normal Gastric Acidity.

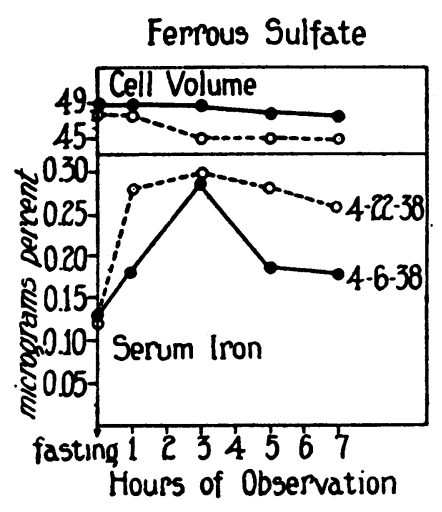

Ferpous Sulfate

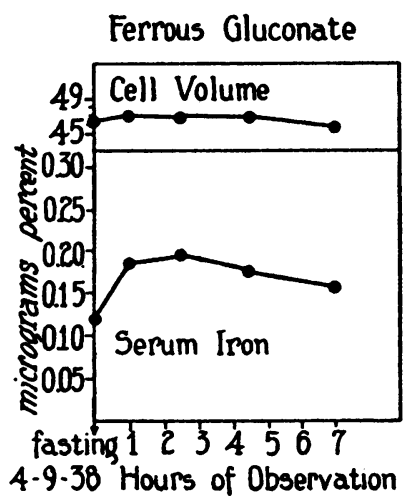

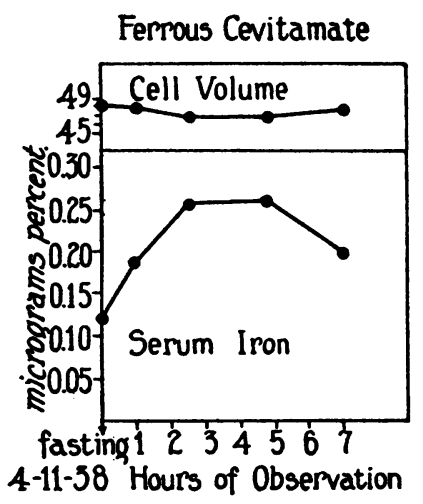

Ferrous Ammonium Sulfate

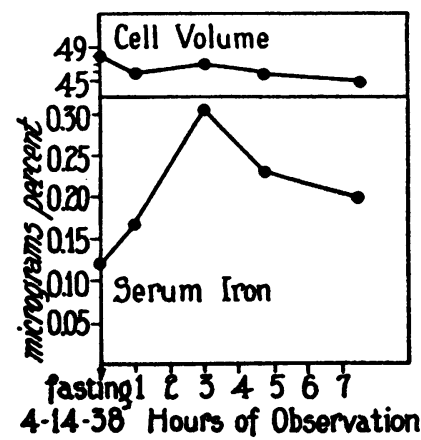

Ferrous Chloride

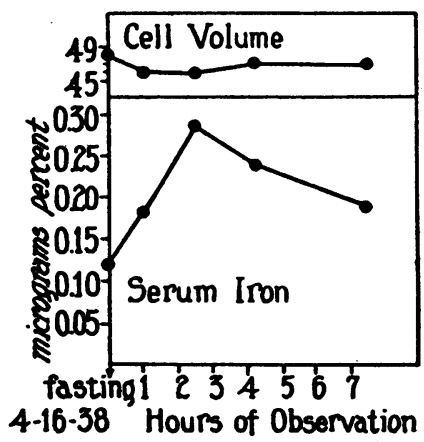

$4 \mathrm{mg}$. $\mathrm{Fe}^{++}$per kilogram of body weight.

Fig. 10. Comparison of Serum Iron Curves Produced by Comparable Amounts of Various Ferrous Salts in a Subject with Normal Gastric Acidity and Normal Hematological Findings 
"ferrostabil" (stabilized ferrous chloride) were capable of producing greater serum iron increases than was ferrum reductum in comparable amounts (27). These results suggest that ease of ionization of the ferrous salts, under those conditions of acidity or alkalinity which prevail in the gastro-intestinal tract, is the important factor in determining their relative rates of absorption. The nature of the anion, except as it influences this factor, would seem to be relatively unimportant.

Comparison of serum iron absorption curves produced by comparable amounts of ferrous and ferric salts of the same anion

There is an increasing volume of experimental evidence which tends to indicate that iron is absorbed from the upper portion of the small intestine as ferrous iron $(32,34 \mathrm{~b}, 41,42)$. That the evidence is not entirely convincing is indicated by recently expressed dissenting views (15, $18,22)$. However, the concept is in accord with the repeatedly demonstrated clinical fact that remissions from iron deficiency anemias, in the human at least, can be produced by smaller amounts of soluble ferrous salts than of soluble ferric preparations (for bibliography, consult review by Heath and Patek-reference 11).

In order to study the question further, serum iron increases produced by the oral administration of comparable amounts of ferrous and ferric salts of the same anions were determined. Heilmeyer and Plötner in 1936 (28a) reported that much greater rises in serum iron were observed following the ingestion of ferrous iron than of similar quantities of ferric. In the great majority of instances, we obtained the same result. Rises in serum iron effected by ferric salts were either negligible or definitely lower in the quantities used than those obtained following ferrous preparations (Figures 11, 15, 16, 21). The data charted in Figure 12 serve as an excellent example of these findings and permit comparison of the curves for both simple (ferrous and ferric sulphate) and combined (ferrous and ferric ammonium sulphate) salts. It is interesting to note that $12 \mathrm{mgm}$. of iron per kilogram of body weight as iron and ammonium citrate were necessary to produce an increase in the serum iron curve comparable to that produced by one-third the quantity of iron as ferrous sulphate.

Occasionally, however, responses following

\section{V.P. $0-3788$ \&, Aged 40 years}

4 mo. Fe per kilogram body weight.

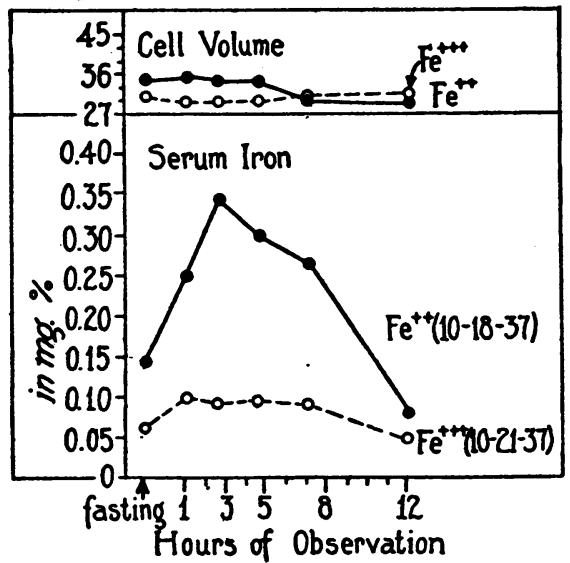

Addisontan Pernicious Anemia Histamine Refractory Achlorhydria

$4 \mathrm{mg}$. Fe per kilogram body weight.

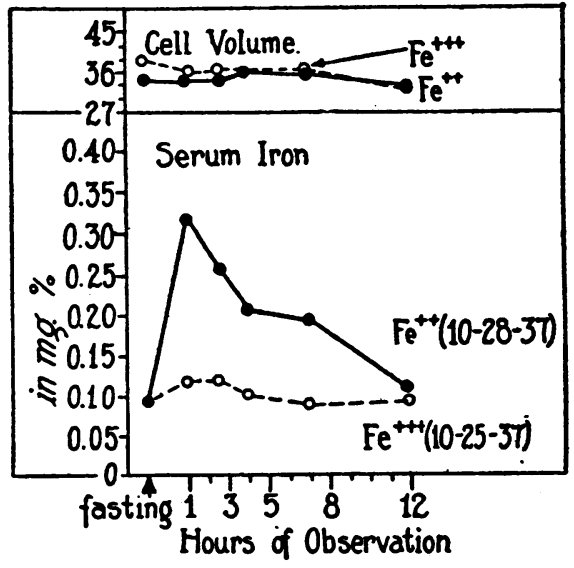

$\mathrm{Fe}^{++}$: curves following $4 \mathrm{mg}$. ferrous iron as ferrous chloride. $\mathrm{Fe}^{+++*}$ : curves following $4 \mathrm{mg}$. ferric iron as ferric chloride.

Fig. 11. Serum Iron Increases following Single Oral Doses of Ferrous and Ferric Chloride in a Subject with Histamine Refractory Achlorh ydria 
0.3987 C.B. o', Aged 28 years, weight 73 kilo.
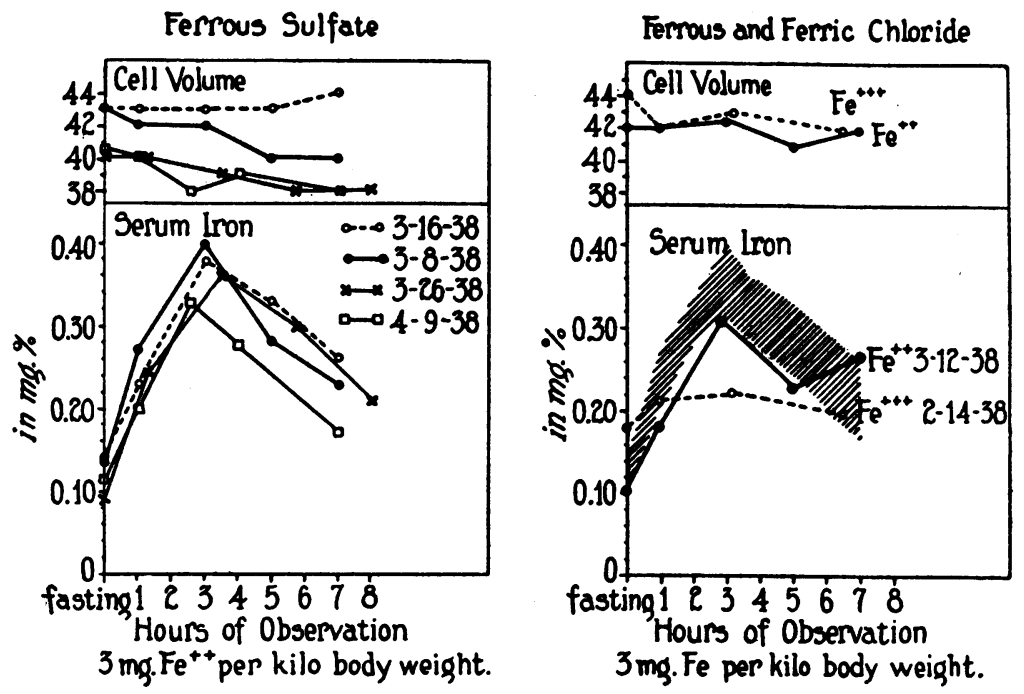

Ferrous and Ferric Ammonium Sulfate.
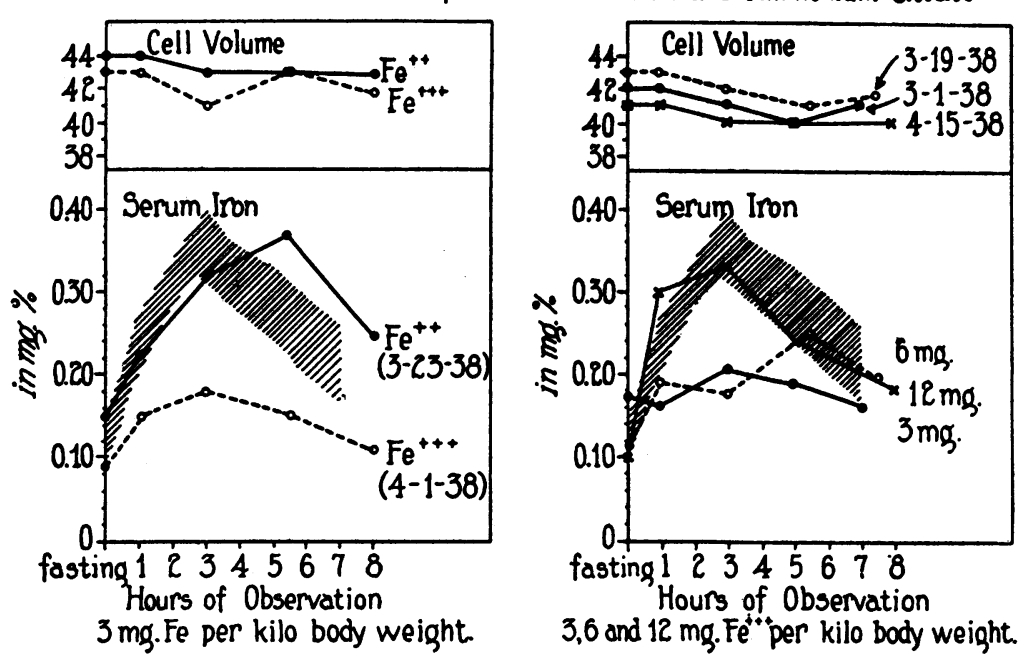

Fig. 12. Comparison of Serum Iron Curves Produced by Comparable Amounts of Various Iron Salts in a Subject with Normal Gastric Acidity and Normal Hematological Findings

ferric iron administration were equally as good as those which followed ferrous iron. One example of that finding has already been presented in Figure 8; another is recorded in Figure 17. Of particular interest in this respect are the observations on $N$. J. T., a white male, 49 years of age, who had a histamine refractory achlorhydria (Figure 13). He was given ferric chloride on each of 2 days. The absorption curves produced agreed well with each other and were definitely lower than those produced by compar- able dosages of ferrous sulphate, ferrous chloride, or ferrous ammonium sulphate. When ferric ammonium sulphate was used, however, there was practically no rise in the serum iron level during the first day, as great a response as was produced by the ferrous salts during the second, and a moderate increase during the third day of observation. The patient had been permitted to take a breakfast of one piece of toast and one cup of black unsweetened coffee two hours before each of the tests was begun. The reason for the dif- 


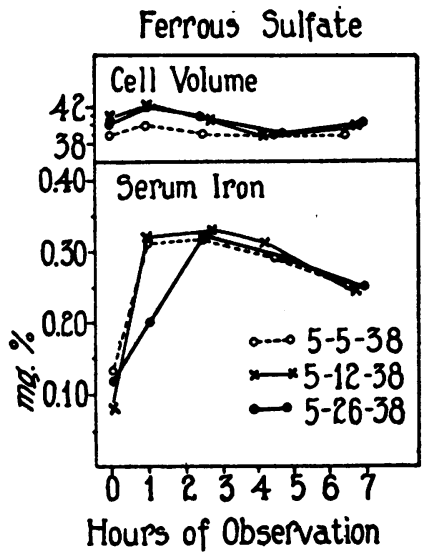

$$
\begin{aligned}
& \text { 0-3926 N.J.T., o., } \\
& \text { Aqed } 49 \text { years. }
\end{aligned}
$$

Addisonian Pernicious Anemia, Induced Remission.

Four milligrams of Fe per kilogram of body weight. One piece of toast and one cup of coffee given two hours prior to observations.
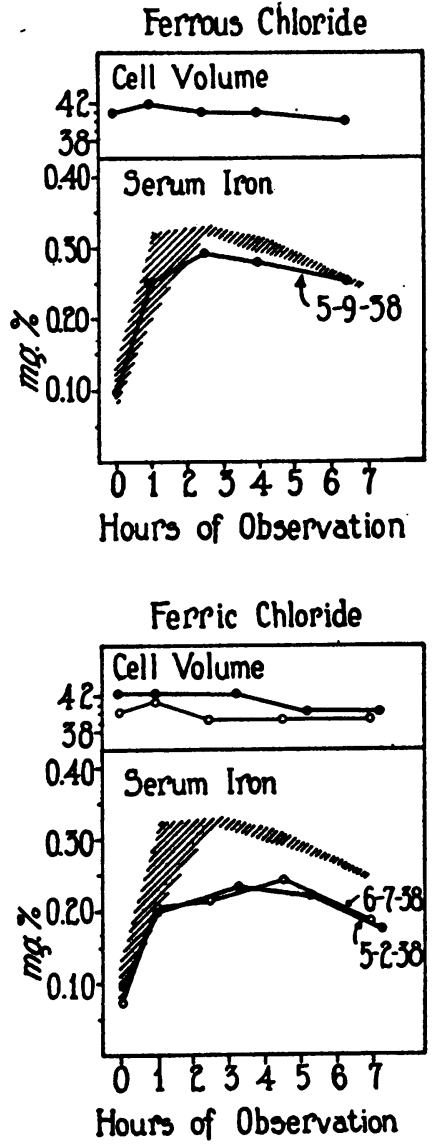
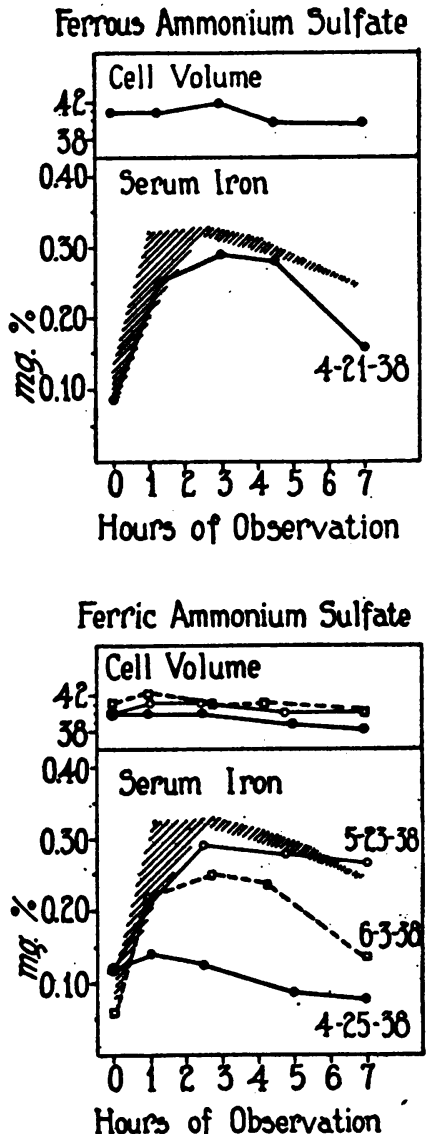

Fig. 13. Increases in Serum Iron following the Oral Administration of Inorganic Soluble Ferrous and Ferric Salts to a Patient with Histamine Refractory Achlorhydria

ference in the degree of absorption produced at different times by identical amounts of the same ferric salt is not immediately obvious unless it is assumed: (1) that it is necessary for ferric iron to be reduced to the bivalent state before it can be absorbed, and (2) that there was a corresponding variation in the reduction potentialities of the small intestine at the time of these 3 trials.

The fact that ferrous salts produced higher rises in serum iron than were usually observed following the oral administration of comparable amounts of corresponding ferric salts adds further weight to the conviction that iron is absorbed from the intestinal tract in a bivalent form. The following observations were even more convincing. To a number of subjects who had failed to show an increase in serum iron following ferric salts, the iron administration was supplemented with either 1.0 gram of cevitamic acid or 1.5 grams of sodium formaldehyde sulphoxylate as reducing substances. Invariably, a good response was obtained, the height of the curves occasionally being higher than those produced by the ferrous salt of the same anion (Figures 15, 16). This latter observation led us to compare the degree of absorption of ferrous salts when given alone with that which occurred when they, too, were supplemented with one of the reducing substances just mentioned. Usually, the serum iron increase was greater with cevitamic acid or sodium formaldehyde sulphoxylate than without it. Negative results were obtained on several patients with two other reducing substances: glutathione in half gram doses (Figures $18,19)$ and methylene blue in gram amounts. Cysteine was not tried. The effectiveness of cevitamic acid in increasing absorption of ferric 
salts in patients with achlorhydria had previously been noted by Heilmeyer (43), who thereupon introduced ferrous cevitamate as a useful form of bivalent iron for therapeutic use. It is reasonable to postulate that, in the case of ferrous salts, cevitamic acid and sodium formaldehyde sulphoxylate aid in preventing partial conversion to the ferric state; and, in the case of ferric salts, aid the reducing mechanisms of the small intestine to make reduction more complete.

When the relatively insoluble ferric phosphate was given by mouth, no increase in serum iron occurred (Figure 14). It has already been indicated that the same was true for ferrous phosphate.

These results add confirmatory data to the mass of experimental and clinical evidence already accumulated which indicates that iron is absorbed from the intestinal tract more readily, if not entirely, in the bivalent state. Serum iron absorption curves were higher as a rule following the ingestion of ferrous salts than of ferric. Frequently, the latter failed to cause any detectable rise in the serum iron fraction whatever. This decreased effectiveness of the ferric salts is in accord with the idea that highly ionized ferric compounds are changed rapidly in the neutral or alkaline medium of the upper small intestines (44) into insoluble ferric hydroxide and other insoluble or non-diffusible ferric compounds (45, $46,47)$. Certain reducing substances, notably cevitamic acid and sodium formaldehyde sulphoxylate, when given orally along with iron, increased the height of the serum iron curves as produced either by ferrous or ferric iron. This suggests that in those instances in which ferric salts caused an appreciable increase in serum iron, the reducing mechanisms in the small intestine were efficient enough to effect a reduction to the ferrous state before great quantities of the ingested compound had been converted to non-ionizable forms, and hence removed from availability to

Addisonian Pernicious Anemia.

Histamine Refractory Achlorhydria.

\section{$0.75 \mathrm{gmFe}$ "as Ferrous Phosphate $(6.76 \mathrm{gm})$}

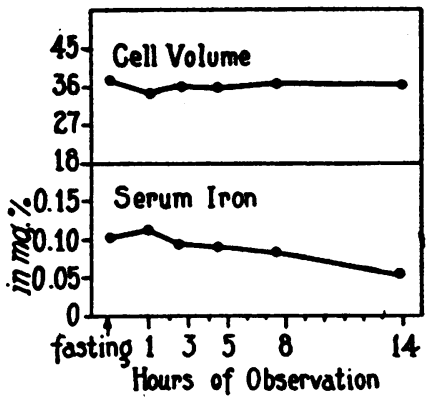

$0.75 \mathrm{gm} . \mathrm{Fe}^{+++}$as Ferric Phosphate $(3 \mathrm{gm})$

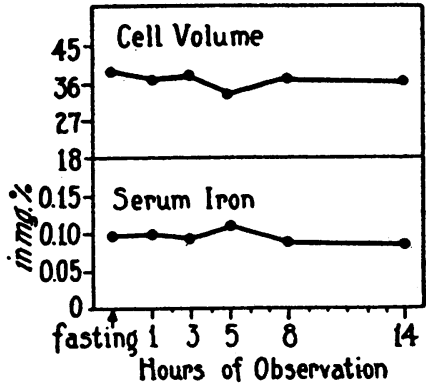

$0.75 \mathrm{gm}$. Fe as Ferrous Phosphate $(6.76 \mathrm{gm})$ plus $100 \mathrm{ce}$. $0.1 \mathrm{~N}$. $\mathrm{HCl}$.

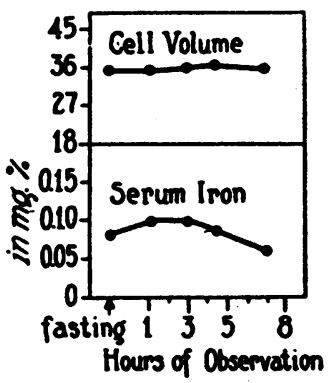

$0.75 \mathrm{gm} . \mathrm{Fe}^{+++t} \mathrm{as}$ Ferric Phosphate $(3 \mathrm{gm}$.) plus $100 \mathrm{cC.} 0.1 \mathrm{~N}$. $\mathrm{HCl}$.

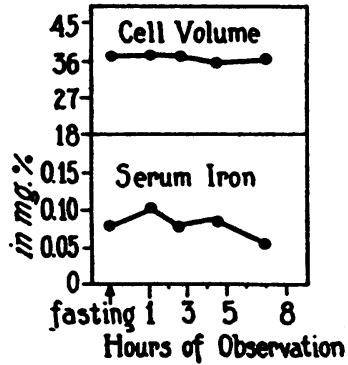

Fig. 14. Serum Iron Values Following Oral Ingestion of Single Doses of Ferrous and Ferric Phosphate 
A.C. $\sigma^{\circ}$, Aged 45 years. Weight 60 kilos. Generalized Arteriosclerosis Normol Gastric Acidity.
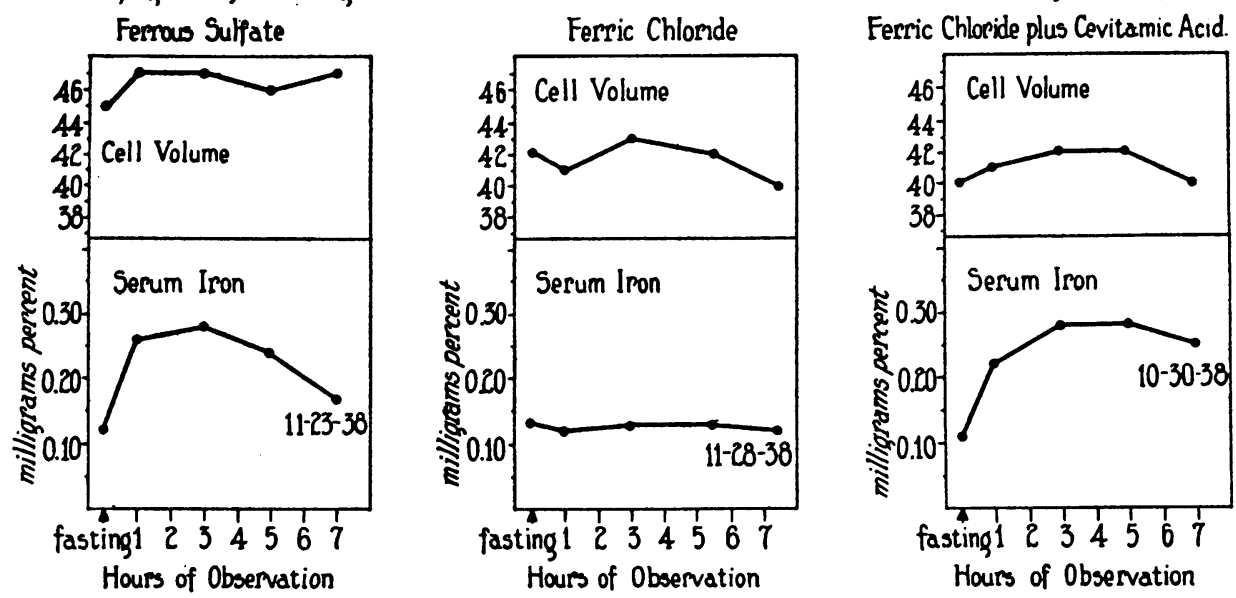

M.B. q. Aged 52 yr Weight. 76 kilos Sciatic Neuritis. Normal Gastric Acidity. Ferric Chloride plus 1.5 gram

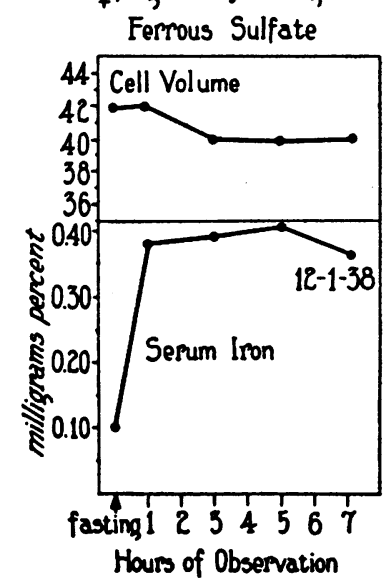

Ferric Chloride

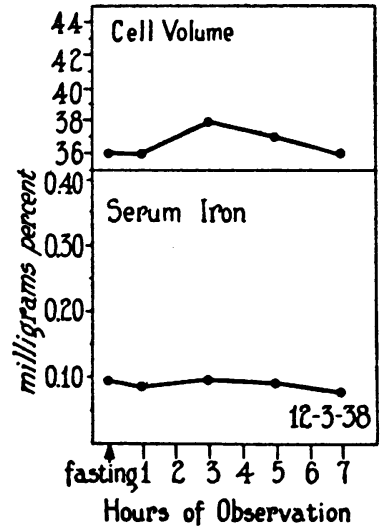

Sodium Formaldehyde Sulfoxylate.

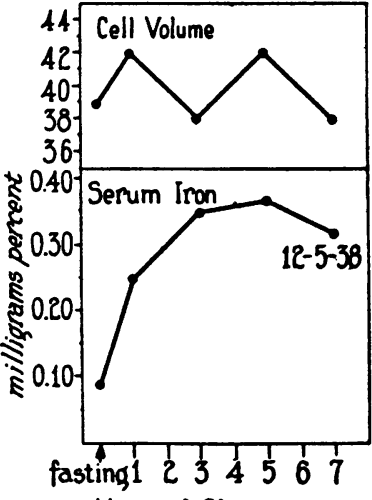

Houps of Observation

4 milligrams $\mathrm{Fe}$ per kilogram body weight.

Fig. 15. Effect of Cenitamic Actd and Sodium Formaldehyde Sulphoxylate on Serum Iron Absorption Curves

the organism. It is to be emphasized again that the failure of a particular iron preparation to cause an increase in the serum iron level does not necessarily mean that none of the metal was absorbed; such a result indicates only that the rate and degree of absorption were not great enough to add iron to the blood stream more rapidly than the combined organs of storage, utilization, and excretion could remove it.

\section{Effect of gastric acidity on the serum iron re- sponses to orally administered ferrous and ferric salts}

While it is generally admitted that normal gastric acidity is necessary for optimal assimilation of food iron $(32,41,42,48,49,50)$, there is some dispute as to its effect upon the absorption of metallic iron salts in therapeutic doses. Mettier and Minot (51) obtained a greater reticulocyte peak when ferric ammonium citrate was given to patients with a hypochromic anemia in an acid-buffered solution than when given in an alkali-buffered medium. The observation was confirmed by Heath (17) and by Minot and Heath (52). Brock and Taylor (53) and Lintzel (32) have shown that the dialysis of soluble inorganic iron salts is hastened by the addition of small amounts of dilute mineral acids and hindered when the solutions are made weakly alkaline. These findings are in accord with those 
of Halvorsen and Starkey who, working with pure solutions of iron, noted that at a $\mathrm{pH}$ above $\mathbf{5 . 0}$ only small concentrations of ferrous, and still smaller concentrations of ferric, iron are present in solution (45). It has been emphasized that the normal acidity of the stomach and duodenal contents is favorable to the formation and preservation of ferrous ions in solution and delays the change into insoluble or undissociated, particularly ferric, compounds $(32,41,42,46,47)$. Nevertheless, good hematologic responses are constantly observed following iron therapy for hypochromic anemia in individuals with complete anacidity; and Barer and Fowler (50) obtained as much retention of iron, when the intake was high, in patients with an achlorhydria as in those with normal gastric acidity.

The problem has already been studied in part with the serum iron absorption curve technic by Heilmeyer and Plötner (28a). These workers noted that when 1 gram of reduced iron was given orally, practically no increase in serum iron occurred in patients with achylia gastrica while an appreciable rise was observed in normal subjects. Our investigations have, for the most part, yielded negative findings. The height of the absorption curves produced by the ingestion of ferrous salts was usually as great in individuals with achlorhydria as in those with normal gastric acidity (Figures 11, 13); occasionally, a smaller rise was obtained (Figure 16). As with normal subjects, ferric salts produced significant serum iron increases in rare instances when achlorhydria was present (Figures 13, 17). Addition of $100 \mathrm{cc}$. of $0.1 \mathrm{~N} \mathrm{HCl}$ to the iron just before its administration failed to increase the height of the absorption curve (Figure 17). If either sodium formaldehyde sulphoxylate or cevitamic acid was given just prior to the iron, increases in the serum iron curves were obtained

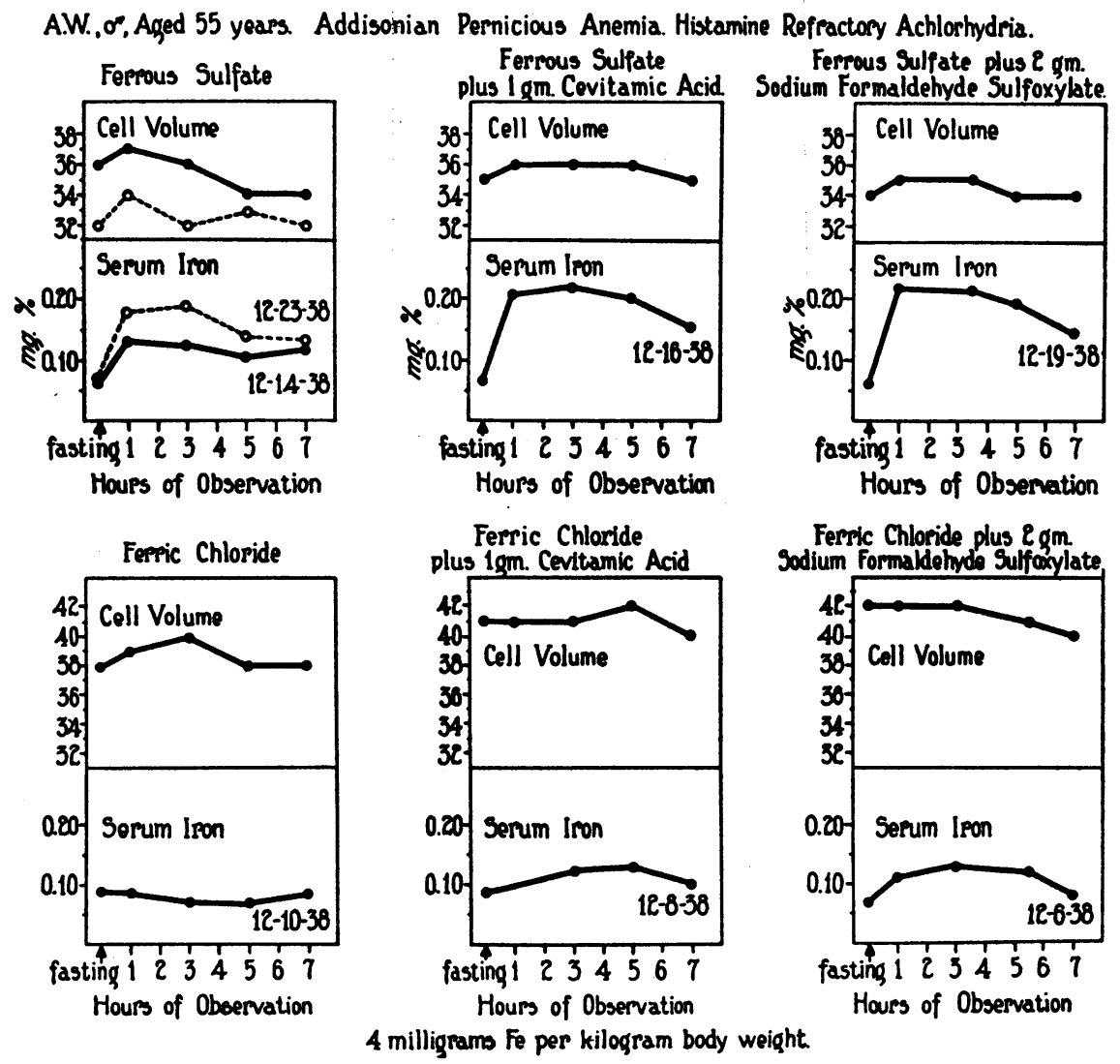

Fig. 16. Effect of Centitamic Acid and Sodium Formaldehyde Sulphoxylate on Serum Iron Absorption Curves 
0-3313 S.B. ó, Aged 77years. Addisonian Pernicious Anemia.

Histamine Refractory Achlorhydria.

$0.75 \mathrm{gm} . \mathrm{Fe}^{++}$.tas Femric Sodium Citrate.
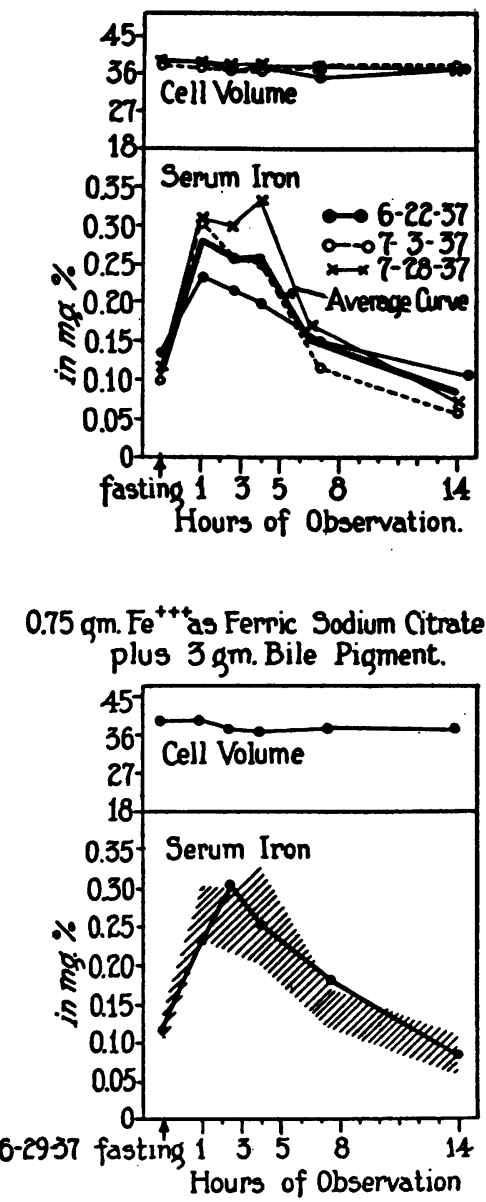

$0.75 \mathrm{gm}$. Fe ${ }^{+++}$as Ferric Sodium Citsate. plus $100 \mathrm{cc} .0 .1 \mathrm{~N}$. HCl.

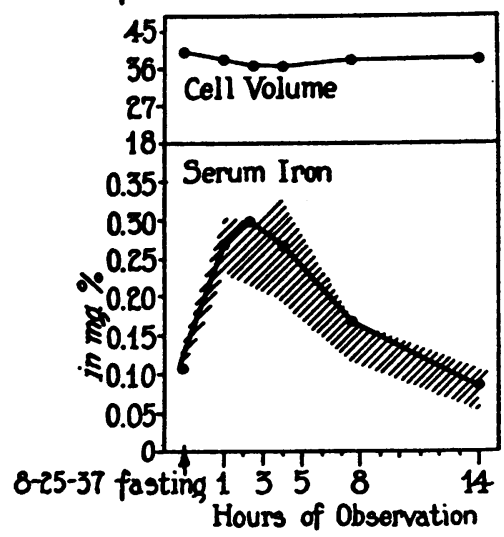

$0.75 \mathrm{gm}$. Fe + as Ferrous Ammonium Sulphate.

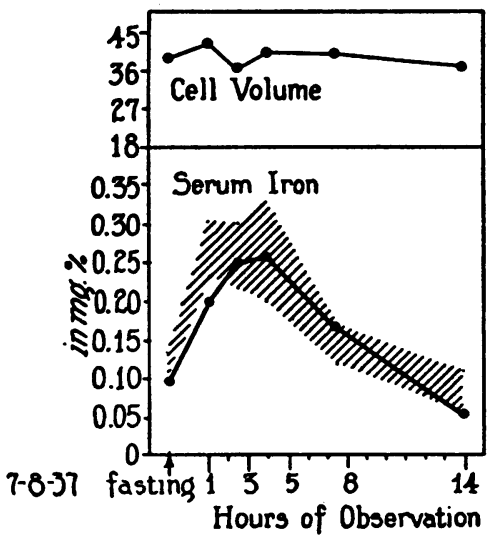

Fig. 17. Study of Seruy Iron Increases following Single Oral Doses of Iron Salts in a Patient with Achlorhydria

in subjects with achlorhydria (Figure 16) just as in patients with normal acidity. The effects with ferric salts were occasionally less dramatic (Figure 16). Attention is called to the fact that the amounts of iron used in these tests were relatively large.

The apparent discrepancy between our results and those of Heilmeyer and Plötner can readily be explained. These latter workers used reduced iron, a form which must be dissolved and ionized in the gastro-intestinal tract before it can be absorbed. Free hydrochloric acid in the gastric contents undoubtedly aids that process. In this respect, the rôle which gastric acidity plays is similar to that for food iron. We, on the other hand, used highly ionized water soluble salts. The effect of gastric acidity on these preparations is apparently to delay the formation of insoluble compounds (at a $\mathrm{pH}$ above 5) until they are brought into contact with the reducing forces of the small intestine. The salts we used, however, were not only acid in reaction but were used in such comparatively large amounts that they almost certainly reached the small intestine before neutralization had taken place. For this reason, this method of studying iron absorption by the serum iron curve technic is probably not particularly applicable to the analysis of the rôle which 
gastric acidity plays under conditions of more moderate intake.

Effect of various miscellaneous substances on the height of serum iron absorption curves

It has been suggested in the recent literature that a number of substances have, in the presence of iron, an additive effect upon hemoglobin production. Patek and Minot (54) described reticulocyte responses to the oral administration of bile pigment following a period of iron medication in patients with hypochromic microcytic anemia. A similar effectiveness for chlorophyll and some of its derivatives was demonstrated by Patek (55). These observations were inter- preted as suggesting that the body can use preformed pyrrol compounds for the building of hemoglobin; no evidence was obtained to indicate that these substances augmented iron absorption. To test that possibility bile pigment, ${ }^{5}$ chlorophyll, and sodium chlorophyllin were given orally along with ferrous sulphate or ferric sodium citrate to several individuals, and the serum iron curves followed. No increase was noted in the height of the curves over that produced by the same amount of the iron alone (Figures 17, $18,19)$.

Barker and D. K. Miller administered orally

${ }^{5}$ The bile pigment used was supplied through the courtesy of Dr. George Minot, Boston.

\section{0-4109 W.W. o". Aged 30 years. Normal Gastric Acidity.}

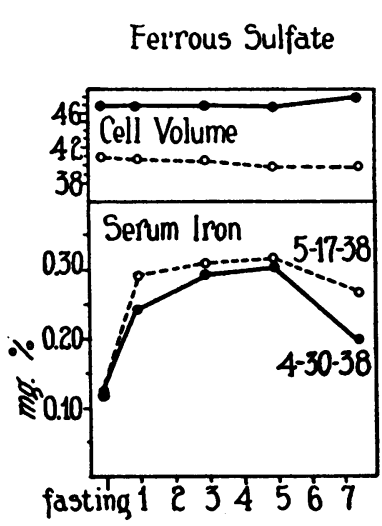

Ferrous Sulfate plus $5 \mathrm{gm}$. Sodium Chlorophyllin

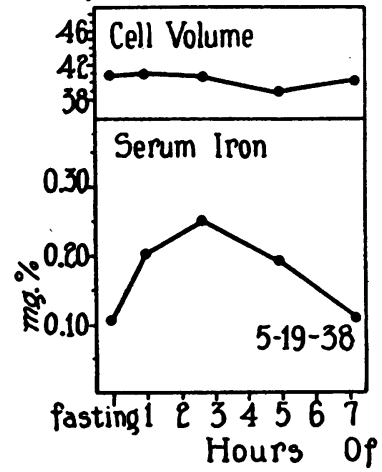

Ferrous Sulfate

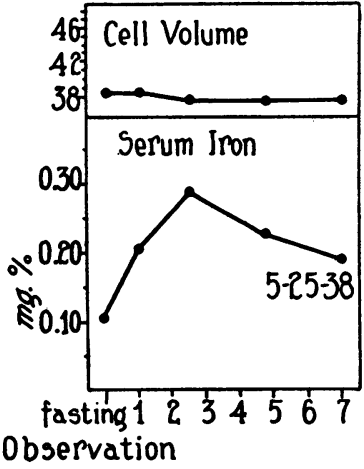

Ferrous Sulfate plus $5 \mathrm{gm}$. Gastric Mucin (suspended in 50 cc. water)

Ferrous Sulfate plus 0.5 gm. Glutathione.
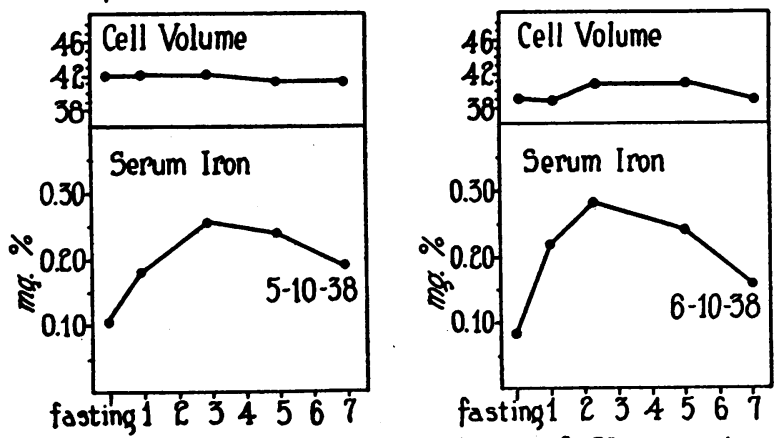

Ferrous Sulfate plus 10 gm. Liver Extract*

Hours of Observation

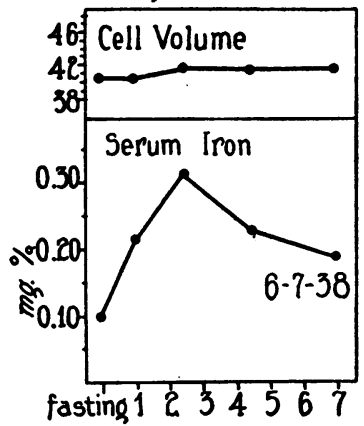

4 milligrams iron per kilogram body weight. "Lilly's Liver Extract" 55 without added iron.

Fig. 18. Effect of Various Supplementary Substances on the Serum Iron Increases Following the Oral Administration of Ferrous Sulphate 
0-3926 N.J.T. ơ.Aged 49 years. Addisonian Pernicious Aneinia, Induced Remission

Ferrous Sulfate

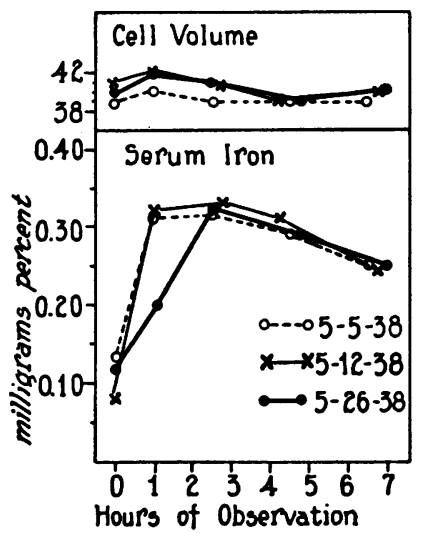

Ferrous Sulfate plus 10 grams Liver Extract.

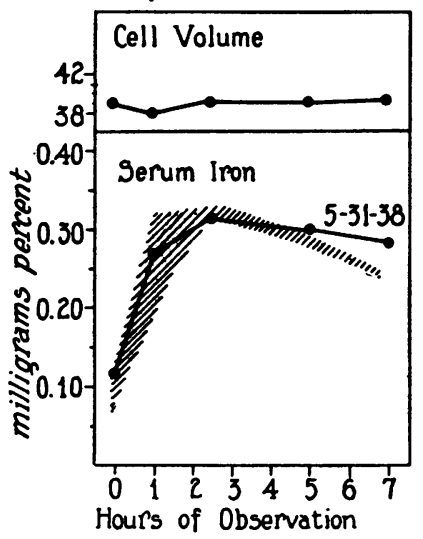

Ferrous Sulfate plus 3 grams Bile Pigment

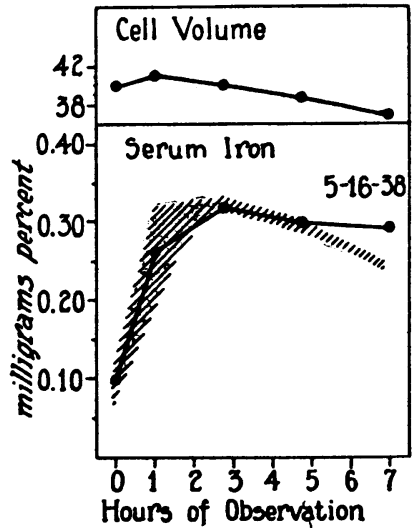

Ferrous Sulfate plus 0.5 grams Glutathione

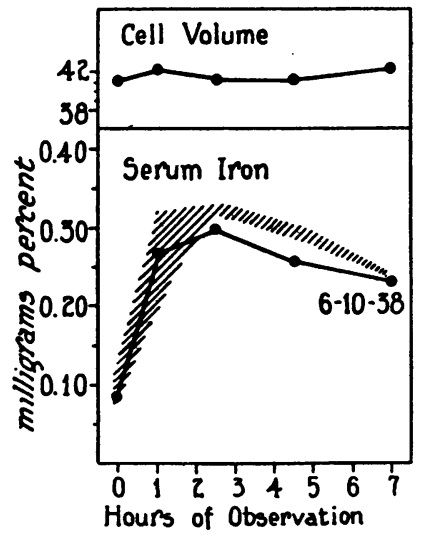

$4 \mathrm{mg}$. Fe per kilogram body weight. 1 piece toast \& 1 cup coffee 2 hours prior to observations.

*Lilly's Liver Extract \# 55 without added iron.

Fig. 19. Effect of Bile Pigment, Liver Extract, and Glutathione on Increases in Serum Iron Following Oral Administration of Ferrous Sulphate to a Patient with Histamine REFRACTORY ACHLORH YDRIA

the secondary anemia liver fraction of Whipple and his coworkers to 11 patients with chronic hypochromic microcytic anemia (56). They concluded that: "it appears likely that the liver fraction contains reticulocytogenic material apart from its iron content," and considered it "conceivable that this liver fraction may improve the absorption or utilization of iron." We obtained, as had Barker and Miller, the liver fraction Number 55 without added iron from Eli Lilly and Company, and gave 10 grams of it by mouth with ferrous sulphate to several patients. The rise in serum iron produced by this joint administration was no greater than that which occurred following the ingestion of the iron salt alone (Figures 18,19$)$.

Heath, Minot, Pohle, and Alstead found that when iron in small doses was administered with relatively large amounts of mucin to cases of chronic hypochromic anemia, its absorption from the intestine was inhibited (57). These workers intentionally used small doses of iron because it 
was felt that if large doses had been given, no inhibiting effect of mucin would have been demonstrable. As has already been emphasized many times, with the serum iron absorption curve technique it is necessary to use relatively large amounts of iron. Accordingly, when the effect of 5 grams of "gastric mucin" ${ }^{6}$ on the absorption curve produced by ferrous sulphate was determined, the amount of the salt used was equivalent to $4 \mathrm{mgm}$. of iron per kilogram of body weight. No alteration in the shape or height of the curve was noted (Figure 18), a fact which confirms the prophesy made by Heath and his coworkers.

The effect of food on the absorption curve of ferrous sulphate was studied in 5 subjects, all of whom had satisfactory serum iron increases when the salt was given after an 18-hour fast. A breakfast of cereal and cream, 2 eggs, 2 strips of bacon, 2 pieces of toast, 1 glass of milk, and 1 cup of coffee was given either immediately before, or immediately after, the ingestion of iron. Two patients, one with normal gastric acidity and the other with a histamine refractory achlorhydria, developed no significant increase in serum iron over the basal level. Two individuals, both with achlorhydria, had a distinct rise in serum ironbut not to the same degree as had occurred following ferrous sulphate alone. The fifth subject, a male with normal gastric acidity, had as great an increase with the food as without it. The reason for this variation in results is not clear. It made no difference whether the breakfast was eaten immediately before, or after, the iron was taken. It may be that in the presence of food, conditions are ripe in the gastro-intestinal tract for the formation of insoluble and undissociable iron compounds. The conclusion is justified that in some individuals, at least, food interferes with the optimal absorption of iron.

\section{Analysis of the question of selective intestinal absorption of iron}

Statement has already been made of the fact that Höber (31), Lintzel (32), and Fontès and Thivolle (33) consider the body capable of assimilating or rejecting iron by a process of se-

- Obtained from Frederick Stearns and Company, Detroit. lective intestinal absorption. In the presence of an iron deficiency, therefore, more iron should be absorbed than under normal circumstances. Heilmeyer recently studied the serum iron absorption curves produced following the ingestion of 1 gram of ferrum reductum in 2 cases of chronic hypochromic anemia before and after therapy (58). Both of his patients secreted adequate amounts of free hydrochloric acid after an alcohol test meal. In each instance, there was very little evidence of absorption before therapy was begun; while, after an iron induced remission had been produced, the serum iron increases were large. In contrast to these results are those recently reported by $\mathrm{Hahn}$ and his associates (26). These latter investigators fed ferric chloride or ferric sulphate containing iron in a radioactive form to normal dogs and to dogs with an iron deficiency. They concluded from increases in serum, organ, and whole blood iron that: " iron is absorbed only in traces by the non-anemic dog but in abundance by the anemic dog depleted of its iron" (26, page 2285).

We have studied several individuals in a similar manner and have obtained divergent results. The serum iron increases which followed the oral administration of ferrous sulphate were determined in these patients with hypochromic, microcytic anemias both before and after therapy. One type of response is illustrated by the data obtained on G.W., an adult male with normal gastric acidity (Figure 9). When the iron deficiency was marked, an increase in serum iron from $0.02 \mathrm{mgm}$. per cent to approximately 0.30 mgm. per cent occurred; after a prolonged period of iron medication, the rise was only from 0.103 mgm. per cent to $0.213 \mathrm{mgm}$. per cent. This finding is in accord with that noted by Hahn and his coworkers. However, there was an occasional patient who showed similar serum iron increases throughout the whole course of the disease. One of these individuals was a young girl who had developed her state of iron deficiency as a result of excessive uterine bleeding secondary to essential thrombocytopenic purpura (Figure 20). Her uterine bleeding was successfully controlled during the period of study by the use of " antuitrin-S." Iron was given in therapeutic amounts and the hypochromia of her red blood cells corrected before splenectomy was performed. $\mathrm{Ab}$ - 

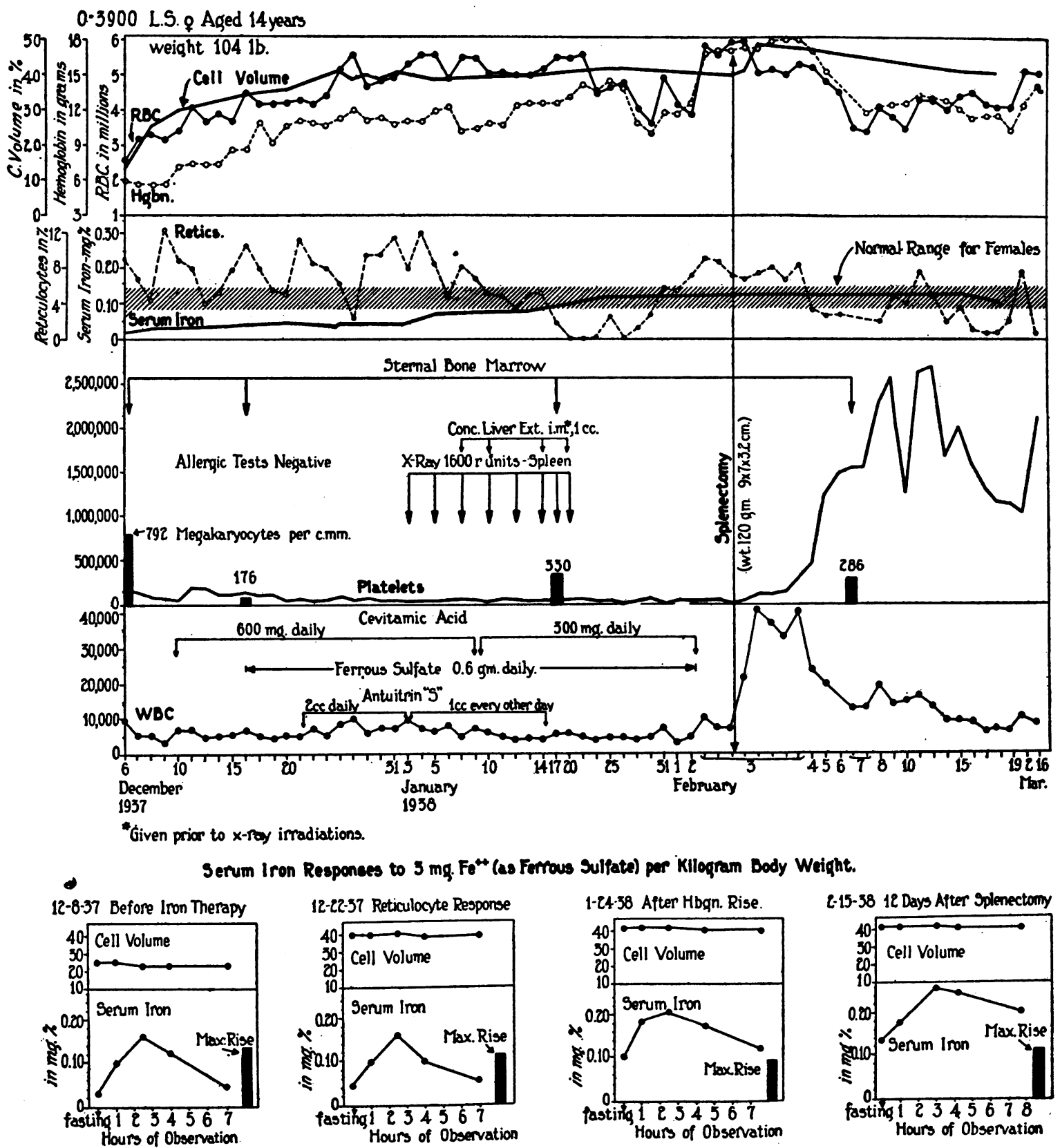

Fig. 20. Response of a Patient with Thrombocytopenic Purpura and Hypochromic Microcytic Anemia to Iron Therapy and to SPLENECtomy

sorption was studied by serum iron curves: (1) before therapy, (2) one week after iron medication was begun, (3) after the mean corpuscular hemoglobin concentration of the erythrocytes had returned to the normal range, and (4) near the end of the convalescent period following splenectomy. The increases above the basal level were essentially the same at all 4 times. It is difficult to correlate this type of result with the selective absorption hypothesis unless it is assumed that, during the iron deficiency periods of study, the iron absorbed into the serum is removed at an abnormally rapid rate by the iron-hungry organs of storage and utilization. 
In the second paper of this series (2, page 630), it was pointed out that 3 patients had failed to show serum iron increases following orally administered amounts of iron that were considerably in excess of the quantities used in the present study. "All three of these patients were acutely ill at the time the observations were made. Any reason otherwise for their failure to respond . . . is not at present apparent." A re-analysis of the data from these 3 individuals reveals that the first 2 had myelophthisic anemias with marked hypoplasia of the erythrocytogenic elements in the bone marrow; the third had pernicious anemia. In all 3 the basal serum iron values were high, and in all 3 the iron storage depots were probably well supplied. This suggested that perhaps we were dealing in these instances with other examples of selective iron absorption, and that the serum iron values failed to show an increase because the intestinal mucosa was functioning by rejecting the iron. In order to test this possibility further, serum iron absorption curves were followed in $\mathbf{5}$ other patients with addisonian pernicious anemia both before therapy and after liver induced remissions. Either ferrous chloride or ferrous sulphate was selected for administration. The data presented in Figure 21 are

J.S $0-3813,0$, Aged 50 years. Relapse, Before Liver Therapy

$4 \mathrm{mg}$. Fe $\mathrm{Fas}^{++}$ferrous sulphate per kilogram body weight.

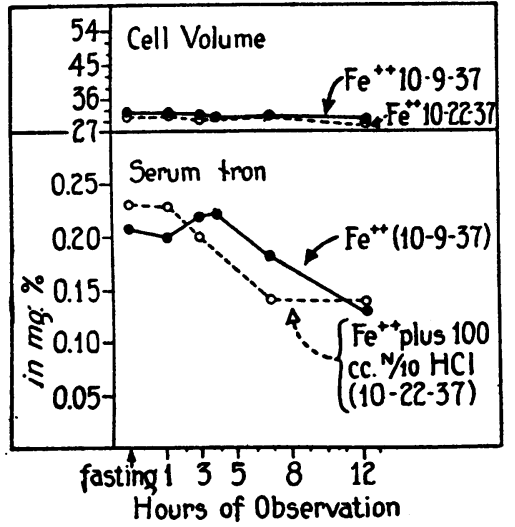

illustrative of the findings obtained in all cases: no serum iron increases occurred during the relapse phases of the disease; but after the peripheral blood level of erythrocytes and hemoglobin had been raised to normal with liver extract, striking increases were noted. On one of the patients, N.J.T., a 49-year-old white male, 3 sets of observations were made (Figure 22): (1) before therapy, (2) at the height of the reticulocyte response to liver medication, and (3) after remission was complete. It is interesting to observe that at the time of the reticulocyte response the serum iron curve rose practically as much as at the time of the final period. A similar study was made on Patient R.R., a white woman in late middle life who had the classical manifestations of the disease (Figure 23). This patient is of particular interest since the reticulocytosis which occurred was induced by the ingestion of large amounts of unautolyzed yeast, a régime that was undertaken to confirm the report of Wintrobe (59). The second observation on this patient was made at the time of the upswing in the reticulocyte curve; the serum iron rise was definite, but less than that which occurred several days later after the peak of the reticulocytosis. Two subsequent increases after further therapy agreed

\section{Addisonian Pernicious Anemia}

After Liver Induced Remission

$4 \mathrm{mg}$ Fe as ferrous sulphate or ferric chloride per kilogram body weight.

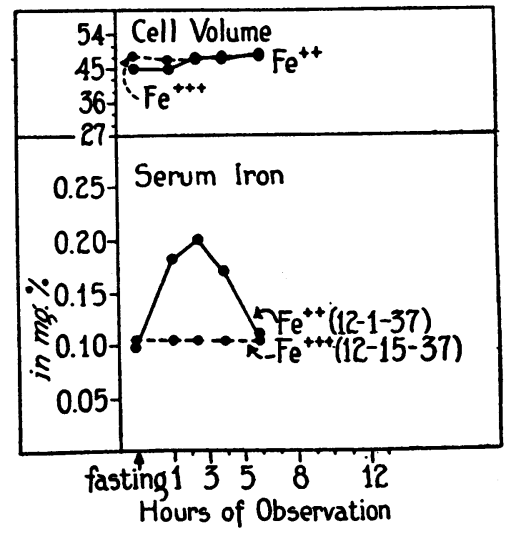

Fig. 21. Serum Iron Responses to Oral Doses of Iron Salts Before and After Liver Therapy in a Patient with Addisonian Pernicious ANEMIA

Iron administered in each instance immediately after fasting specimen. 
0-3926 N.J.T. ơ. Aged 49 years. Weight 63 kilos. Addisonian Pernicious Anemia.

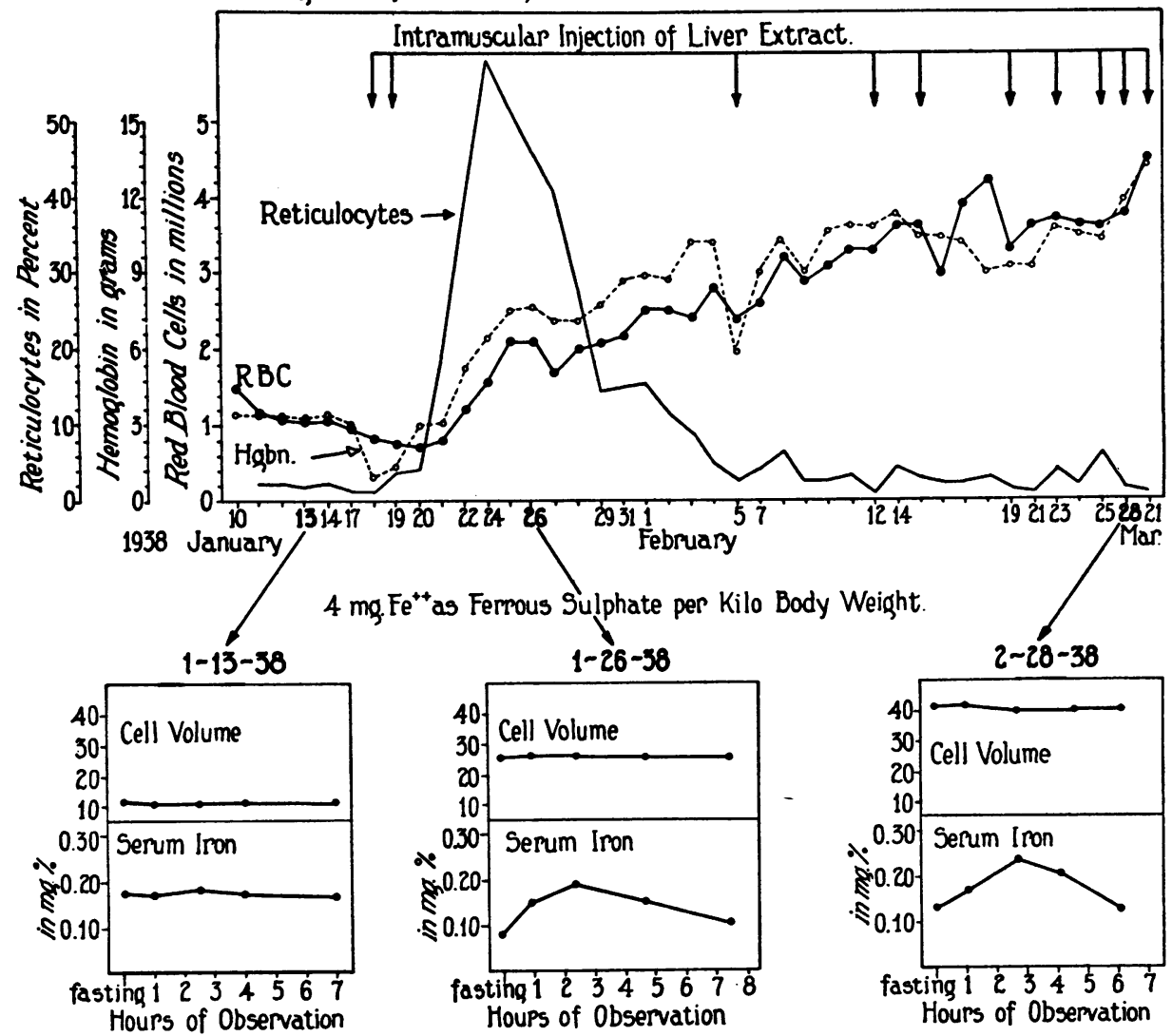

Fig. 22. Serum Iron Increases Following Oral Administration of Ferrous Sulphate in a Patient with Addisonian Pernicious Anemia Before and After Liver Therapy

well in order of magnitude with that observed at the height of the reticulocyte response. These findings are not too readily explained on the basis of selective intestinal absorption of iron. At the time of the reticulocyte response the storehouses in these patients must undoubtedly have had an adequate supply of iron still retained. However, because of the increased synthesis of hemoglobin in the bone marrow (2), the fasting serum iron level had returned to normal or below normal values. It may be that that change in the physiological equilibrium was sufficient in itself to stimulate the intestinal mucosa to begin again its process of assimilating iron. It is interesting to note in this connection that the height to which the serum iron values rose in the absorptive phase after liver therapy was rarely higher than the fasting serum iron level had been during relapse.

A serious objection to this explanation arose when it was observed that several patients with advanced carcinomatosis and one during the terminal phases of chronic glomerular nephritis failed to develop an increase in serum iron following ferrous sulphate in spite of the fact that their initial levels were normal or subnormal. It may. be, therefore, that this absorptive difficulty is common to all patients who are critically ill; at least no absorptive increases in serum iron have ever been demonstrated in critically ill individuals. Groen (60), in addition, has reported that glucose is absorbed less readily by patients with pernicious anemia while in relapse than when in remission. The change in absorption produced by liver extract may, therefore, be a general rather than a specific one.

Two pertinent observations have been made: (1) at least some patients with iron deficiencies have greater proportionate serum iron increases 

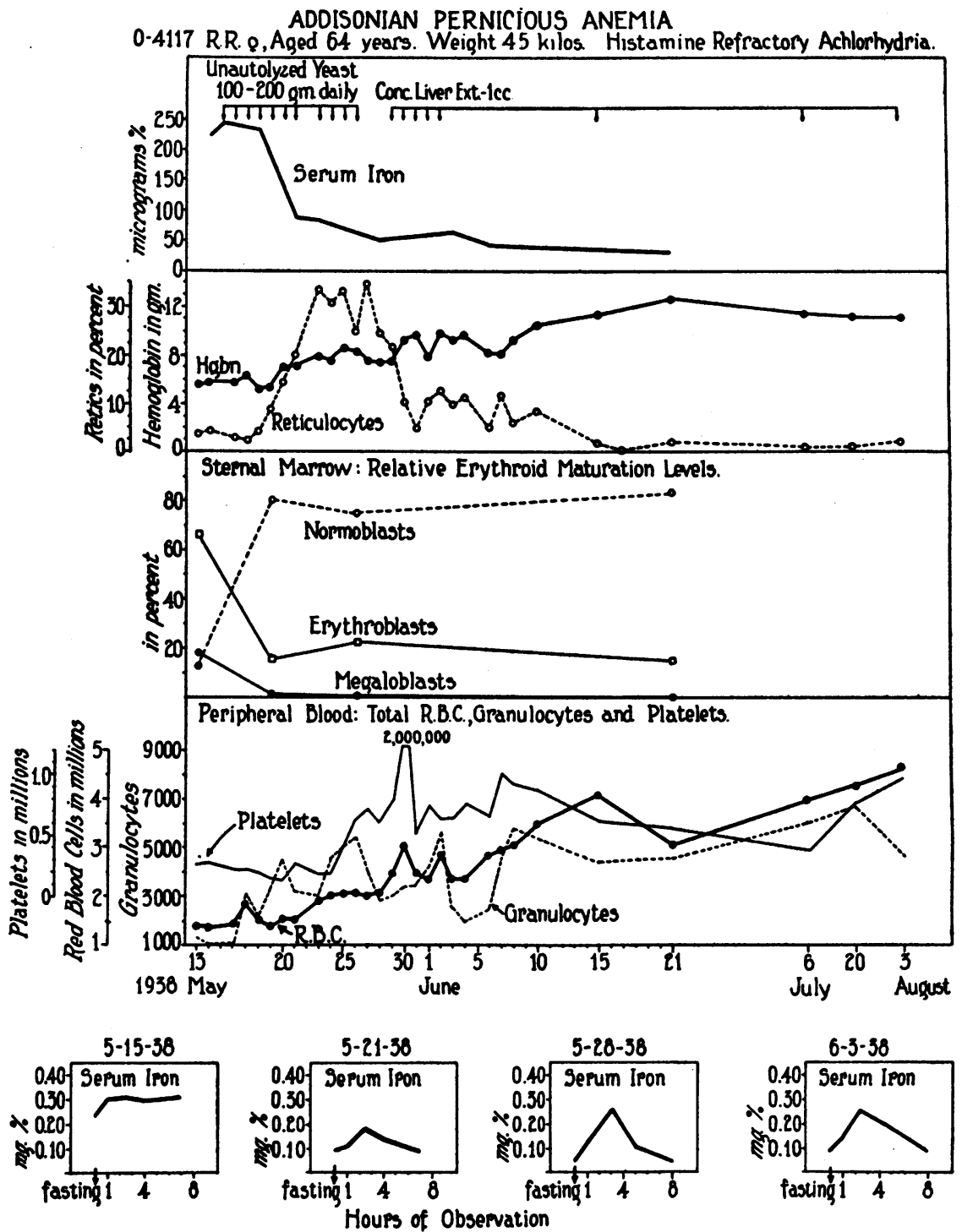

$4 \mathrm{mg}$. Fet as ferrous ammonium sulfate per kilogram body woight.

Fig. 23. Serum Iron Increases Following Oral Administration of Ferrous Ammonium Sulphate in a Patient with Addisonian Pernicious Anemia Before and After Therapy (Massive Doses of Unautolyzed Brewer's Yeast)

to the same amount of soluble iron salts than do normal individuals, and (2) patients with pernicious anemia in relapse fail to show any response of the serum iron fraction to orally administered iron salts during relapse but have good increases after specific therapy has been instituted. These facts are compatible with the concept of selective intestinal absorption of iron, but offer no conclusive proof that the intestine actually possesses that ability.

\section{SUMMARY AND CONCLUSIONS}

Comprehensive reviews of iron metabolism which include an analysis of the investigative approach to the problem of iron absorption have been made recently by Robscheit-Robbins (61), McCance and Widdowson (19), Hahn (18), and Heath and Patek (11). The present investigation directs attention to the fact that, since serum iron has been demonstrated to be transport iron $(2,4,28 \mathrm{~b})$, a new objective approach to the study 
of iron resorption from the gastro-intestinal tract is available in the measurement of serum (transport) iron increases following the oral administration of iron in various forms. It has been emphasized that serum iron is influenced by a number of physiological factors, some of which affect its removal from the blood stream. The method, therefore, does not measure the total amount of absorption, but rather the fact and the degree of absorption. It is applicable to the comparative study of serum iron responses in the same individual to different forms of iron under varying gastro-intestinal conditions, and in contrasting states of hematopoietic activity. With its use we have demonstrated that:

1. Absorption of iron from the gastro-intestinal tract was reflected directly by an increase in serum iron and not through an intermediate rise in the iron of the thoracic duct lymph.

2. The disappearance of intravenously injected soluble iron salts from the blood stream occurred slowly during a period of hours.

3 . The height of the serum iron increase following the ingestion of iron was directly proportional to the quantity given up to that point at which intestinal irritation was great enough to interfere materially with intestinal motility.

4. When identical amounts of ferrous sulphate were given to any subject in hematologic equilibrium, the serum iron curves produced closely paralleled each other.

5. Water soluble, highly ionized ferrous salts produced comparable increases in serum iron values when given in proportionate amounts to patients with either an achlorhydria or normal gastric acidity. These findings suggest that the ease of ionization of ferrous salts, under those conditions of acidity or alkalinity present in the gastro-intestinal tract, is the important factor in determining their relative rates of absorption. The nature of the anion, except as it influences this factor, would seem to be relatively unimportant.

6. In the majority of instances, the serum iron absorption curves were higher following the ingestion of ferrous than of ferric salts. When ferric salts were given to subjects along with relatively large amounts of either cevitamic acid or sodium formaldehyde sulphoxylate, the serum iron responses were uniformly as good as those produced by ferrous salts of the same anion. These two reducing agents were likewise frequently capable of increasing the rise obtained following the ingestion of ferrous preparations. These findings are presented as additional evidence for the conviction that iron is absorbed largely, if not entirely, in the ferrous form.

7. Differences in gastric acidity exerted no measurable effect on the serum iron absorption curves following the oral administration of ferrous or ferric salts. It is suggested, however, that such large amounts of the various iron salts were used that their own acidity was sufficiently great to overcome the effect of naturally occurring hypochlorhydria in delaying the formation of insoluble and undissociated iron compounds which may occur above $\mathrm{pH} 5$.

8. No increases in serum iron were obtained following administration of the insoluble ferrous and ferric phosphate.

9. When subjects were permitted to take food just prior to, or immediately following, the ingestion of iron salts there was observed frequently, but not constantly, a smaller rise in the serum iron than occurred under fasting conditions.

10. Bile pigment, chlorophyll and its derivatives, the secondary anemia liver fraction, and gastric mucin, under the conditions of these experiments, failed to alter the height or character of the serum iron absorption curves produced by ferrous sulphate.

11. Patients with an iron deficiency anemia frequently showed evidence of greater absorption of iron before therapy than after they had been adequately treated. On the other hand, patients with addisonian pernicious anemia in relapse showed no demonstrable increase in their already higher than normal serum iron values when ferrous salts were given orally; following a liver induced remission, however, normal absorption curves were readily obtained. These observations are compatible with the hypothesis that the intestinal mucosa may, under certain circumstances and within certain limits, assimilate or reject iron according to the body's need. They do not, however, constitute conclusive evidence for this hypothesis.

From the data available in the literature and 
that which this communication presents, the following picture of iron absorption may tentatively be constructed. When ingested iron reaches the stomach, it is subjected to the influences of the prevailing acidity. The free hydrochloric acid normally present apparently has two functions: (1) to ionize and dissolve iron not already present in solution nor in an ionized state; and (2) to delay the formation of insoluble and undissociated iron compounds. Since these form at a $\mathrm{pH}$ above 5.0, the change to them would tend to occur to some degree, at least, in the stomachs of patients with achlorhydria. When the iron is delivered to the duodenum, it is subjected to two influences: the alkaline intestinal juices and certain reducing agents. The latter tend to reduce any trivalent iron to the ferrous form before the change to non-ionizable salts has occurred. Iron is absorbed from the intestinal tract largely, if not entirely, as ferrous iron. The degree to which ferric salts are assimilated would seem to depend upon the capacity of the intestinal contents to reduce them. It is the consensus of opinion that absorption takes place largely in the upper portion of the small intestine. When iron is absorbed, it passes directly into the blood plasma and is not to any extent collected by the intestinal lymph channels. As more data are accumulated, this working hypothesis based on information now available will undoubtedly be altered and enlarged.

\section{BIBLIOGRAPHY}

1. Moore, Carl V., Arrowsmith, Wm. R., Quilligan, J. J., Jr., and Read, J. T., Studies in iron transportation and metabolism. I. Chemical methods and normal values for plasma iron and "easily splitoff" blood iron. J. Clin. Invest., 1937, 16, 613.

2. Moore, Carl V., Doan, Charles A., and Arrowsmith, Wm. R. Studies in iron transportation and metabolism. II. Mechanism of iron transportation: its significance in iron utilization in anemic states of varied etiology. J. Clin. Invest., 1937, 16, 627.

3. Moore, Carl V., Minnich, Virginia, and Welch, Jo, Studies in iron transportation and metabolism. III. The normal fluctuations of serum and "easily split-off" blood iron in individual subjects. J. Clin. Invest., 1939, 18, 543.

4. Moore, Carl V., and Doan, Charles A., Correlation of serum iron, bone marrow and blood cell changes following specific therapy in the macrocytic anemias. Arch. Path. (Proc.), 1937, 23, 738.
5. Heubner, W.,

(a) Bemerkung zur Eisentherapie. Ztschr. f. Klin. Med., 1924, 100, 675.

(b) Uber "Organische" Eisenpräparate. Klin. Wchnschr., 1926 5, 588.

6. Posener, $\mathrm{K}$., Ueber die theoretischen Grundlagen der Eisentherapie. Therap. d. Gegenw., 1927, 68, 541.

7. Wiechowski, W., Die Eisentherapie im Lichte der neueren Forschung. Med. Klin., 1927, 23, 1765.

8. Starkenstein, E., Die Derzeitigen Pharmakologischen Grundlagen einer Rationellen Eisentherapie. Klin. Wchnschr., 1928, 7, 217.

9. Fullerton, H. W., Treatment of hypochromic anaemia with soluble ferrous salts. Edinburgh M. J., 1934, 41, 99.

10. Witts, L. J., Therapeutic action of iron. Lancet, 1936, $1,1$.

11. Heath, Clark W., and Patek, Arthur J., Jr., Anemia of iron deficiency. Medicine, 1937, 16, 267.

12. Fowler, W. M., and Barer, A. P., Iron retention following use of ferric ammonium citrate in hypochromic anemia. J. A. M. A. (Proc.), 1935, 104, 144.

13. Widdowson, E. M., and McCance, R. A., Absorption and excretion of iron before, during and after period of very high intake. Biochem. J., 1937, 31, 2029.

14. Abbott, W. O., and Miller, T. G., Intubation studies of human small intestine; technic for collection of pure intestinal secretion and for study of intestinal absorption. J. A. M. A., 1936, 106, 16.

15. Whipple, G. H., and Robscheit-Robbins, F. S., Iron and its utilization in experimental anemia. Am. J. M. Sc., 1936, 191, 11.

16. Heath, C. W., Strauss, M. B., and Castle, W. B., Quantitative aspects of iron deficiency in hypochromic anemia, parenteral administration of iron. J. Clin. Invest., 1932, 11, 1293.

17. Heath, C. W., Oral administration of iron in hypochromic anemia. Arch. Int. Med., 1933, 51, 459.

18. Hahn, P. F., Metabolism of iron. Medicine, 1937, 16, 249.

19. McCance, R. A., and Widdowson, E. M.,

(a) Absorption and excretion of iron. Lancet, 1937, 2, 680 .

(b) Absorption and excretion of iron following oral and intravenous administration. J. Physiol., 1938, 94, 148.

20. Groen, J., and Taylor, F. H. L., Absorption of iron compounds from upper part of small intestine. Proc. Soc. Exper. Biol. and Med., 1937, 36, 694.

21. Brock, J. F., Relation between hypochromic anaemias and iron deficiency. Brit. M. J., 1937, 1, 314.

22. Brock, J. F., and Hunter, D., Fate of large doses of iron administered by mouth. Quart. J. Med., 1937, $6,5$.

23. Fowler, W. M., and Barer, A. P., Retention and utilization of orally administered iron. Arch. Int. Med., 1937, 59, 561. 
23a. Fowler, W. M., Barer, A. P., and Spielhagen, G. F., Retention and utilization of small amounts of orally administered iron. Arch. Int. Med., 1937, 59, 1024.

24. Barkan, G., and Schales, O.,

(a) Chemischer Aufbau und physiologische Bedeutung des "leicht abspaltbaren" Bluteisens. 13. Mitteilung in der Reihe der Eisenstudien. Ztschr. f. physiol. Chem., 1937, 248, 96.

(b) Bildungsmöglichkeiten und Eigenschaften der Pseudohämoglobine. 14. Mitteilung in der Reihe der Eisenstudien. Ztschr. f. Physiol. Chem., 1938, 253, 83.

25. Cortis-Jones, B., and Lemberg, R., The chemical mechanism of hemoglobin breakdown. Proc. of the 16th International Physiological Conference, Kongressbericht II, p. 251.

26. Hahn, P. F., Bale, W. F., Lawrence, E. O., and Whipple, G. H., Radioactive iron and its metabolism in anemia. J. A. M. A., 1938, 111, 2285.

27. Thoenes, F., and Aschaffenburg, R., Der Eisenstoffwechsel des Wachsenden Organismus. Abhandlung aus d. kinderheilkunde und ihren Grenzgebieten, Karger, Berlin, 1934.

28. Heilmeyer, Ludwig, and Plötner, Kurt,

(a) Eisenmangelzustände und ihre Behandlung. Klin. Woch., 1936, 15, 1669.

(b) Das Serumeisen und die Eisenmangelkrankheit (Pathogenese, symptomologie und therapie). 1937. Gustav Fischer, Jena.

29. Gaule, J., Der Nachweis des Resorbirten Eisens in der Lymphe des Ductus thoracicus. Deutsche med. Wochenschr., 1896, 22, 373.

30. Müller, F., Beiträge zur Frage nach der Wirkung des Eisens bei Experimentell Erzeugter Anämie. Arch. f. Path. Anat., 1901, 164, 436.

31. Höber, R., Ueber Resorption im Darm. Arch. f. d. ges. Physiol., 1903, 94, 337.

32. Lintzel, W., Neuere Ergebnisse der Erforschung des Eisenstoffwechsels. Ergebn. d Physiol., 1931, 31, 844.

33. Fontès, G., and Thivolle, L., Bilan du Fer chez le Chien rendu anémique par Saignées répétés. Compt. Rend. Soc. de Biol., 1932, 109, 911.

34. Starkenstein, E., and Weden, H.,

(a) Uber das anorganische Eisen des Organismus. Arch. f. Exper. Path. u. Pharmakol., 1928, 134, 274.

(b) Uber das Schicksal des Eisens im Organismus nach Zufuhr von complexen Verbindungen mit anorganisch und organisch gebundenem Eisen. Ibid., 1930, 150, 354.

35. Barkan, G.,

(a) Eisenstudien, Die Verteilung des leicht abspaltbaren Eisens zwischen Blutkörperchen und Plasma und sein Verhalten unter Experimentellen Bedingungen. Ztschr. f. Physiol. Chem., 1927, 171, 194.

(b) Uber das Verhalten von anorganischem Eisen nach Zusatz zum Blute. 7. Mitteilung in der Reihe der Eisenstudien. Ibid., 1933, 216, 17.
36. Polson, C. J.,

(a) Fate of colloidal iron administered intravenously. J. Path. and Bact., 1928, 31, 445.

(b) Fate of colloidal iron administered intravenously; long experiments. Ibid., 1929, 32, 247.

37. Hahn, P. F., and Whipple, G. H., Iron metabolism; its absorption, storage and utilization in experimental anemia. Am. J. M. Sc., 1936, 191, 24.

38. Starkenstein, E., and Harvalik, Z., Uber eine im intermediären Eisenstoffwechsel entstehende Ferriglobulinverbindung. Arch. f. exper. Path. $u$. Pharmakol., 1933, 172, 75.

39. Starkenstein, E., Utber die Resorbierbarkeit von Eisenverbindungen aus dem Verdauungskanal. Arch. f. exper. Path. u. Pharmak. d., 1927, 127, 101.

40. Wallbach, G., Die Eisenresorption als Voraussetzung der Anämiebehandlung. Weitere Untersuchungen über die verschiedenen Resorptionserscheinungen der einzelnen Eisenpräparate. Folia haemat., 1936, 54, 201.

41. Starkenstein, E., Handbuch der allgemeinen Hämatologie, Band II, 2. [Hirschfeld, H., and Hittmair, A., eds.] Berlin, Urbau, 1934, p. 1384.

42. Reimann, F., and Fritsch, F., Vergleichende Untersuchungen zur therapeutischen Wirksamkeit der Eisenverbindungen bei den sekundären Anämien. Ztschr. f. klin. Med., 1930, 115, 13.

43. Heilmeyer, L., Personal communication.

44. Robinson, C. S., The hydrogen ion concentration of the contents of the small intestine. J. Biol. Chem., 1937, 108, 403.

45. Halvorsen, H., and Starkey, R., Studies on the transformation of iron in nature. I. Theoretical considerations. J. Phys. Chem., 1927, 31, 626.

46. Smythe, C. V., and Schmidt, C. L. A., Studies on the mode of combination of iron with certain proteins, amino acids and related compounds. J. Biol. Chem., 1930, 88, 241.

47. Tompsett, S. L.,

(a) Studies of the complexes of iron with various biological materials. Biochem. J., 1934, 28, 1802.

(b) The copper and "inorganic" iron contents of human tissues. Biochem. J., 1935, 29, 480.

48. Kellogg, F., and Mettier, S. R., Effect of alkaline therapy for peptic ulcer on utilization of dietary iron in regeneration of hemoglobin. Arch. Int. Med., 1936, 58, 278.

49. Strauss, Maurice B., Rôle of the gastro-intestinal tract in conditioning deficiency disease. . . J. A. M. A., 1934, 103, 1.

50. Barer, A. P., and Fowler, W. M., Influence of gastric acidity and degree of anemia on iron retention. Arch. Int. Med., 1937, 59, 785.

51. Mettier, S. R., and Minot, G. R., Effect of iron on blood formation as influenced by changing acidity of gastroduodenal contents in certain cases of anemia. Am. J. M. Sc., 1931, 181, 25.

52. Minot, G. R., and Heath, C. W., Response of reticulocytes to iron. Am. J. M. Sc., 1932, 183, 110. 
53. Brock, J. F., and Taylor, F. H. L., Diffusion of soluble iron compounds in vitro. Effect of acids, bases and electrolytes. Biochem. J., 1934, 28, 447.

54. Patek, A. J., Jr., and Minot, G. R., Bile pigment and hemoglobin regeneration; effect of bile pigment in cases of chronic hypochronic anemia. Am. J. M. Sc., 1934, 188, 206.

55. Patek, A. J., Jr., Chlorophyll and regeneration of the blood. . . . Arch. Int. Med., 1936, 57, 73.

56. Barker, W. H., and Miller, D. K., Clinical observations on Whipple liver fraction (secondary anemia fraction). Am. J. M. Sc., 1938, 195, 287.

57. Heath, C. W., Minot, G. R., Pohle, F. J., and Alstead, G., Influence of mucin upon absorption of iron in hypochromic anemia. Am. J. M. Sc., 1938, 195, 281.

58. Heilmeyer, L., Uber die Pathogenese der echten Chlorose. . . . Deutsches. Arch. f. Klin. Med., 1938, 182, 150.

59. Wintrobe, M. M., The successful treatment of pernicious anemia by means of non-autolyzed yeast. J. Clin. Invest., 1938, 17, 501. (Proc.)

60. Groen, J., Absorption of glucose from small intestine in deficiency disease. New England J. Med., 1938, 218, 247.

61. Robscheit-Robbins, F. S., Regeneration of hemoglobin and erythrocytes. Physiol. Rev., 1929, 9, 666. 